\title{
Microstructural Study of a Mg-Zn-Zr Alloy Hot Compressed at a High Strain Rate
}

\author{
Jing You ${ }^{1}$, Yingjie Huang ${ }^{1}$, Chuming Liu ${ }^{1}$, Hongyi Zhan ${ }^{2, *}$, Lixin Huang ${ }^{3}$ and Guang Zeng ${ }^{1, * \mathbb{C}}$ \\ 1 School of Materials Science and Engineering, Central South University, Changsha 410083, China; \\ Jing_Y@csu.edu.cn (J.Y.); alex.huang@csu.edu.cn (Y.H.); cmliu@csu.edu.cn (C.L.) \\ 2 China Science Lab, General Motors Global Research and Development, Shanghai 201206, China \\ 3 CITIC Dicastal Co., Ltd., Qinhuangdao 066000, China; huanglixin@dicastal.com \\ * Correspondence: henry.zhan@gm.com (H.Z.); g.zeng@csu.edu.cn (G.Z.)
}

Received: 7 April 2020; Accepted: 6 May 2020; Published: 20 May 2020

\begin{abstract}
Understanding the correlation of plasticity with deformation and dynamic recrystallization (DRX) behaviors, in magnesium $(\mathrm{Mg}$ ) alloys deformed under high-strain-rate conditions, is increasingly important for wrought $\mathrm{Mg}$ processing. In the present study, a ZK30 (Mg-2.61\%Zn- $0.66 \% \mathrm{Zr}$ by weight percent (wt.\%)) alloy in the as-forged state was hot compressed to various strain levels at a temperature of $350{ }^{\circ} \mathrm{C}$ and a strain rate of $10 \mathrm{~s}^{-1}$. Heterogeneous deformation and dynamic recrystallization (DRX) behaviors of the complicated microstructures in the deformed samples were analyzed via a grain-partitioning approach based on intra-grain misorientation analysis from electron back-scattered diffraction (EBSD). The ZK30 alloy showed excellent formability, remaining intact at a true strain of -1.11 . Continuous dynamic recrystallization (CDRX) and discontinuous dynamic recrystallization (DDRX) via grain boundary corrugation/bulging are the dominant mechanisms for the relaxation of strain energy during hot compression. Initial Zr-rich coarse grains undertook a significant portion of the plastic strain as the compression progressed, reflected by the increased misorientations within their interior and marked change in their aspect ratios. The results indicate that the excellent plasticity of the as-forged ZK30 alloy can be attributed to the operative CDRX mechanisms and the reduced deformation anisotropy of Zr-rich coarse grains containing Zn-Zr nano-precipitates.
\end{abstract}

Keywords: $\mathrm{Mg}-\mathrm{Zn}-\mathrm{Zr}$ alloys; EBSD; hot compression; dynamic recrystallization; bimodal microstructure

\section{Introduction}

Magnesium (Mg) alloys, due to their low densities and high specific strength, are attractive for lightweight applications, catering to the demand of the automobile industry for reduced emissions and improved fuel economy [1]. However, the formability of hexagonal-close-packed (HCP) metals in plastic deformations is deficient due to inadequate independent slip systems [2]. Therefore, most of the $\mathrm{Mg}$ components in vehicles are made by casting, especially high-pressure die casting, to take advantage of the castability and low melting points of Mg alloys [3].

Referring to previous studies [4-9], Mg wrought alloys are generally suitable for processing at temperatures higher than $300{ }^{\circ} \mathrm{C}$ and strain rates lower than $1 \mathrm{~s}^{-1}$ to avoid cracking. At higher temperatures and lower strain rates, non-basal slip systems can be readily activated to accommodate strains, and dynamic recrystallization (DRX) can operate for relaxation of stress concentrations. However, processing at elevated temperatures and low strain rates is energy consuming and unfavorable to productivity, which induces high costs. Employment of high strain rates in the hot deformation of $\mathrm{Mg}$ alloys may be a potential solution for cost reduction. Moreover, a higher strain rate will contribute to finer DRXed grains in the final microstructure, which will enhance mechanical properties. However, 
it is challenging to deform $\mathrm{Mg}$ alloys to a large strain level at strain rates higher than $1 \mathrm{~s}^{-1}$ during hot deformation. A common phenomenon related to cracking and failure is severe shear localization occurring during deformation at a high strain rate $[4,6,10]$. There are two mainstream explanations for the formation of shear bands in Mg alloys. The first is that compression along the c-axes of grains tends to activate compression/double twinning in the basal-textured $\mathrm{Mg}$ samples. High activity of basal slip and repetitive DRX will occur within the twins since their orientations are more geometrically preferable for basal slip comparing with the basal-textured matrix [7,11-14]. This contributes to strain localization and the formation of macro-shear-bands (macro-SBs). An alternative explanation is to correlate shear localization with DRXed grains whose orientations are randomized from the basal texture. A 'necklace structure' consisting of DRXed grains of random orientations formed around the coarse-grained matrix of basal texture favors basal slip. Hence, more plastic strains will partition into the 'necklace structure' to form shear bands $[15,16]$. Since a high strain rate will enhance twinning activities and the sensitivity of basal slip to grain orientation, Mg alloys are more vulnerable to shear localization when being hot deformed at high strain rates. Moreover, DRX kinetics are lower under high-strain-rate conditions.

In recent years, Zhu et al. [17] reported that high-strain-rate rolling can be performed on the ZK60 $\mathrm{Mg}$ alloy at an equivalent strain rate as high as $\sim 9.6 \mathrm{~s}^{-1}$ at $300{ }^{\circ} \mathrm{C}$. An intact sheet was successfully produced. The authors attributed the excellent plasticity of the ZK60 alloy to the twinning-induced DRX (TDRX) mechanism [18,19] which effectively released strain energy. It is worth noting that the as-received material used for hot rolling/compression in their experiments was in the as-cast state and had an average grain size of $\sim 150 \mu \mathrm{m}$. This coarse-grained microstructure is beneficial for the operation of TDRX. However, in industrial production, the as-received materials are usually extruded, hot rolled or forged rather than cast alloys. Mg alloys after plastic deformation processing have a much finer grain size. In general, a fine grain size will suppress the activation of twinning [20]. In this case, the deformation and DRX behaviors of Mg alloys of fine grain size in the hot deformation at high strain rates remain unknown and require further studies.

It is industrially important to manufacture wrought $\mathrm{Mg}$ components by hot deformation (over $300{ }^{\circ} \mathrm{C}$ ) with a high production rate. To explore this feasibility, a ZK30 (Mg-2.61\%Zn- $0.66 \% \mathrm{Zr}$ by $\mathrm{wt} . \%$ ) alloy in the as-forged state was hot compressed at a high strain rate of $10 \mathrm{~s}^{-1}$ at $350{ }^{\circ} \mathrm{C}$ to various strain levels in this study. The initial grain size in the microstructure of the as-forged ZK30 alloy was refined compared to the as-cast microstructure. For industrial production, it is not feasible to apply strain rates much higher than $10 \mathrm{~s}^{-1}$ due to a concern over safety and operability. Therefore, the testing strain rate in the present study was set to $10 \mathrm{~s}^{-1}$. In general, $\mathrm{Mg}$ alloys will be heated to over $300^{\circ} \mathrm{C}$ prior to plastic forming. Therefore, the testing temperature in the present study was set to $350{ }^{\circ} \mathrm{C}$. Systematic microstructural characterizations by correlative optical microscopy $(\mathrm{OM})$ and electron backscattering diffraction (EBSD) were conducted on the hot-compressed samples. The correlation of plasticity with deformation and DRX behaviors of the as-forged ZK30 alloy under the present deformation condition is discussed.

\section{Experimental Procedures}

A ZK30 (Mg-2.61\%Zn-0.66\%Zr by wt. \%) forged blank formed at $390^{\circ} \mathrm{C}$, as shown in Figure 1a, was supplied by CITIC Dicastal Co., Ltd. (Qinhuangdao, Hebei, China), for study. Here, the axis direction, radial direction, and tangential direction of the forged blank are referred to as $A D, R D$, and TD, respectively. Cylindrical samples with a dimension of $\varnothing 10 \mathrm{~mm} \times 12 \mathrm{~mm}$ were cut from the rim with their long axes aligned along the RD for hot compression tests. Uniaxial hot compression tests were conducted on a Gleeble-3180 thermal-mechanical simulation testing system. Nickel-based lubricants and graphite sheets were used on both ends of the sample to reduce friction. Before the tests, two thermocouples were welded on the surface of the sample for temperature control. Then, the sample was heated at a heating rate of $5{ }^{\circ} \mathrm{C} / \mathrm{s}$ to $350^{\circ} \mathrm{C}$ and held for $120 \mathrm{~s}$ to ensure uniform temperature distribution. The sample was uniaxially compressed at $350^{\circ} \mathrm{C}$ and $10 \mathrm{~s}^{-1}$ followed by water quenching. 
Since direct quenching in the chamber is not allowed, there was an interval of approximately 4-5 s between the end of compression and the water quench. The true strains $\left(\varepsilon_{\mathrm{t}}\right)$ of compression tests at a strain rate $(\dot{\varepsilon})$ of $10 \mathrm{~s}^{-1}$ were set to $-0.22,-0.40,-0.69$, and -1.11 , i.e., height reductions of $0.2,0.33$, 0.5 , and 0.67 , respectively. For comparison, compression tests at $350{ }^{\circ} \mathrm{C}$ and $10^{-3} \mathrm{~s}^{-1}$ were conducted following the same procedure, with $\varepsilon_{\mathrm{t}}$ of -0.40 and -1.11 . Measurements were repeated $2-3$ times for each condition to ensure the reproducibility of stress-strain curves.
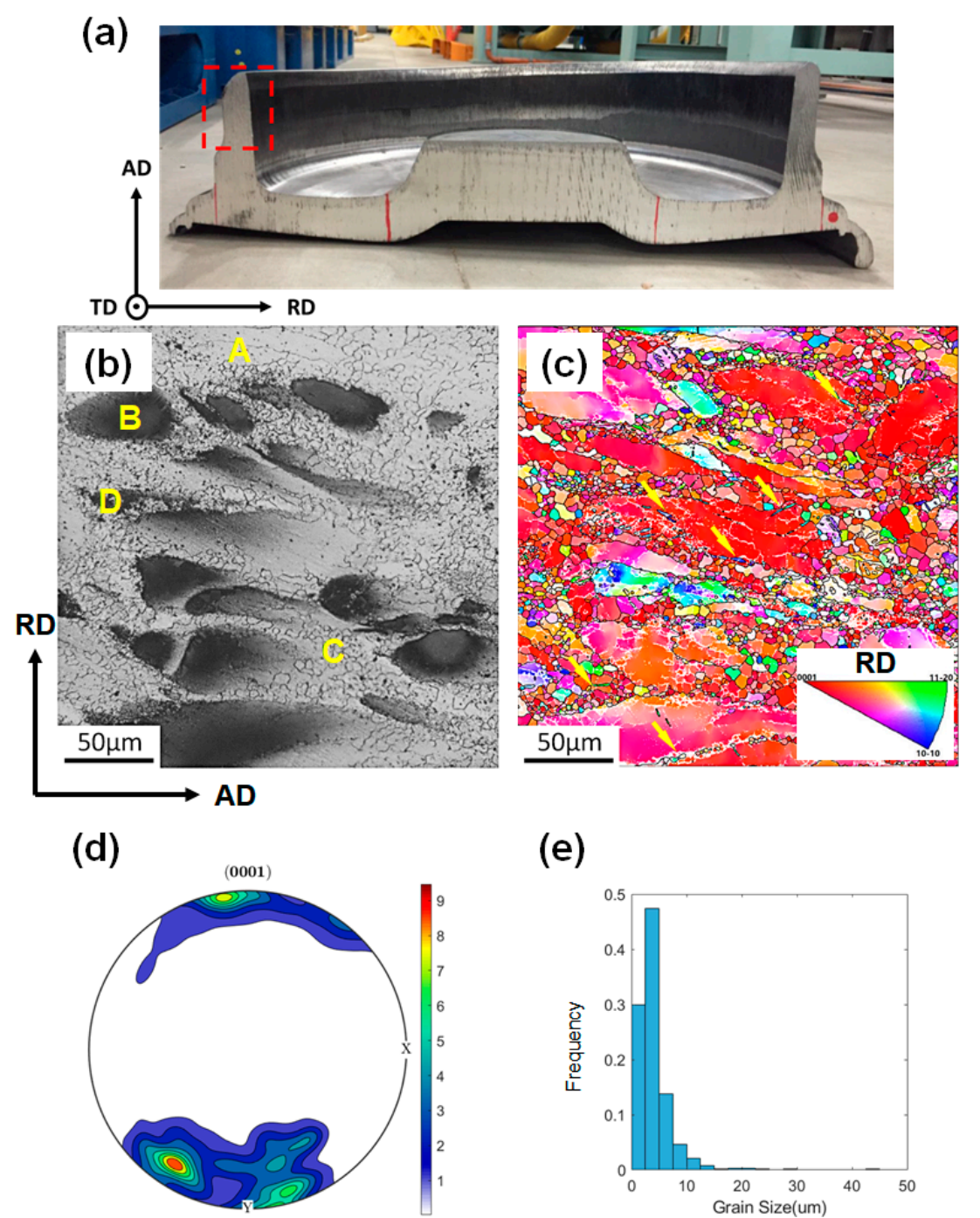

(e)

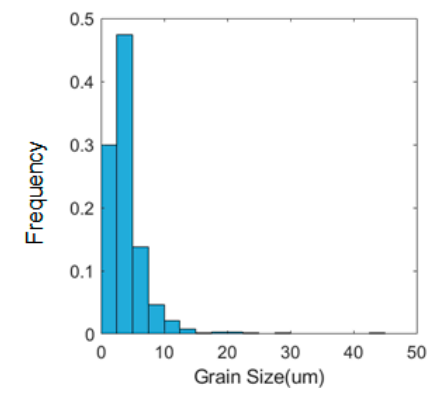

Figure 1. Initial microstructure of the as-received sample: (a) location of sampling for hot compression, $(\mathbf{b}, \mathbf{c})$ corresponding optical microscope $(\mathrm{OM})$ and electron back-scattered diffraction (EBSD) micrographs of (a), (d) corresponding (0001) pole figure, and (e) grain size distribution calculated from the EBSD dataset of (c). The step size for EBSD measurements was $0.3 \mu \mathrm{m}$.

The microstructures of tested samples were characterized using a Leica DIM5000 optical microscope (OM) (Wetzlar, Germany) and a Zeiss AURIGA field-emission gun scanning electron microscope (SEM) equipped with an EBSD detector (Zeiss, Heidenheim, Germany). The samples were cross sectioned transversely along the centerline and then ground and polished following standard procedures. Samples for OM and SEM observations were etched by a solution of $0.5 \mathrm{wt} \%$ oxalic acid, 0.5 vol. $\%$ nitric acid, and $0.5 \mathrm{vol} . \%$ acetic acid for $15 \mathrm{~s}$. Electrochemical polishing was performed on polished samples for EBSD characterization, using a solution of 3 vol.\% perchlorate and 1 vol.\% nitric acid ethanol at $-40{ }^{\circ} \mathrm{C}$ for $90 \mathrm{~s}$. The step size applied in the EBSD characterization was between $0.12-0.3 \mu \mathrm{m}$, depending on the grain size of the detected samples. EBSD datasets were analyzed using MATLAB ${ }^{\mathrm{TM}}$ 
9.2 (Mathworks, Natick, MA, USA) with the MTEX 5.28 toolbox [21]. Transmission electron microscopy (TEM) samples were collected by the focused ion beam (FIB) lift-out technique using an FEI Helios NanoLab 600 dual beam system. TEM characterization was performed on a Titan G2 60-300 microscope at $300 \mathrm{kV}$ (FEI, Hillsboro, OR, USA).

\section{Results}

\subsection{As-Forged Microstructure}

The as-received material revealed a typical partially DRXed microstructure with bimodal features, as shown in Figure 1b. Most coarse grains were in dark contrast, which is caused by the dispersion of the refined $\mathrm{Zn}-\mathrm{Zr}$ phase [22-24]. Zr particles, which acted as nucleation substrates for $\alpha-\mathrm{Mg}$, were dissolved into the $\mathrm{Mg}$ matrix during solidification. Hence, the $\mathrm{Zn}-\mathrm{Zr}$ phase precipitated out from the as-cast $\mathrm{Mg}$ dendrite supersaturated in $\mathrm{Zr}$ in the subsequent annealing process [25]. The pinning force exerted on mobile dislocations by $\mathrm{Zn}-\mathrm{Zr}$ precipitates retarded the movement of dislocations, leading to the partial DRX behavior of ZK30 during forging. The as-forged microstructure can be divided into four types of regions: the $\mathrm{Zr}$-lean coarse-grained region (marked by ' $\mathrm{A}$ ' in Figure $1 \mathrm{~b}$ ), the $\mathrm{Zr}$-rich coarse-grained region (marked by ' $\mathrm{B}$ ' in Figure 1b), the Zr-lean fine-grained region (marked by ' $\mathrm{C}$ ' in Figure 1b), and the Zr-rich fine-grained region (marked by ' $\mathrm{D}$ ' in Figure 1b). Coarse grains were surrounded by fine DRXed grains. Figure 1c shows the inverse pole figure (IPF) map of the same region as Figure $1 \mathrm{~b}$. A small quantity of twin-like features can be observed as indicated by yellow arrows. The corresponding pole figure in Figure $1 \mathrm{~d}$ reveals that most grains tended to align their c-axes to the RD. In addition, it is noted that the maximum intensity of the basal pole was slightly inclined to the AD. The grain size distribution is shown in Figure 1e. Nearly $80 \%$ of grains were smaller than $5 \mu \mathrm{m}$ in the as-forged microstructures.

\subsection{OM Characterization of the Compressed Microstructures}

Uniaxial hot compressions were performed on cylindrical samples with the loading axis parallel to the $\mathrm{RD}$ as shown in Figure 2a. Figure $2 \mathrm{~b}$ provides the compressive true stress-strain curves of ZK30 samples hot compressed at $\dot{\varepsilon}$ of $10 \mathrm{~s}^{-1}$ at $350{ }^{\circ} \mathrm{C}$. Strain hardening continued until the peak stress reached $>100 \mathrm{MPa}$ at $\varepsilon_{\mathrm{t}}$ of $\sim 0.17$. Stress gradually declined beyond the peak due to DRX softening. The tested samples remained intact up to $\varepsilon_{t}$ of -1.11 as shown in Figure 2c, showing excellent plasticity under the present deformation condition. It is noted that all the samples showed anisotropic flow with the major axis of the cross-section developed toward the AD. For consistency, all the deformed samples were observed on the AD-RD section viewed along the TD. Optical images in Figure 2d indicate that macro-SBs (as indicated by yellow arrows) developed early at $\varepsilon_{\mathrm{t}}$ of -0.22 with a weak contrast. The contrast of macro-SBs increased with increasing strains. Optical images of macro-SBs (as delineated by yellow arrows) at higher magnifications are shown in Figure 3. It is evident that the contrast of macro-SBs is due to the significant shearing of $\mathrm{Zr}$-rich coarse grains.

Figure 4 shows the detailed microstructural evolution of ZK30 alloys hot deformed to various strains at $\dot{\varepsilon}$ of $10 \mathrm{~s}^{-1}$. The characterizations were conducted on the central location of macro-SBs. Though the strain rate employed was as high as $10 \mathrm{~s}^{-1}$, few twinning signatures were observed. Only a small quantity of twin-like features existed within coarse grains. Twinning activity was suppressed due to the synergic effects of the refined grain size and elevated testing temperature. At $\varepsilon_{t}$ of -0.22 , it was surprising to find that extensive growth of $\mathrm{Zr}$-lean equiaxed grains occurred (Figure $4 \mathrm{~b}$ ) in comparison to the as-received material (Figure 4a). Most coarse grains did not show a sensible morphological change. As $\varepsilon_{\mathrm{t}}$ increased to -0.40 , the aspect ratios of coarse grains noticeably increased (Figure $4 \mathrm{c}$ ). As indicated by yellow ellipses in Figure 4c, DRXed grains nucleated around the Zr-rich coarse grains, which were finer than the initial DRXed grains in the as-received microstructure. As the deformation proceeded to $\varepsilon_{\mathrm{t}}$ of -0.69 and -1.11 , the fraction of refined DRXed grains increased and the aspect ratio of coarse grains was significantly altered. 
(a)
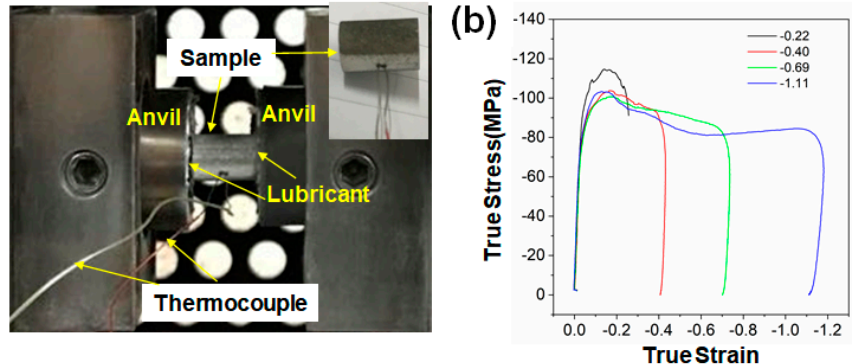

(c)

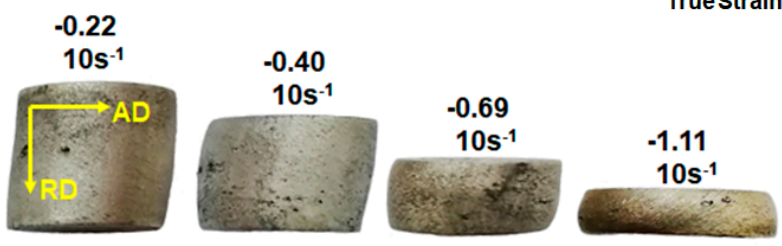

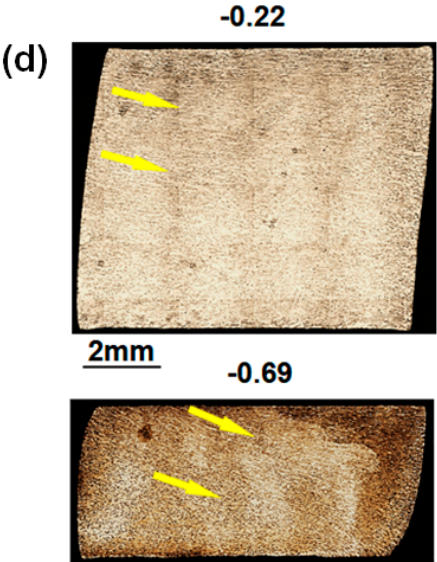

$2 \mathrm{~mm}$

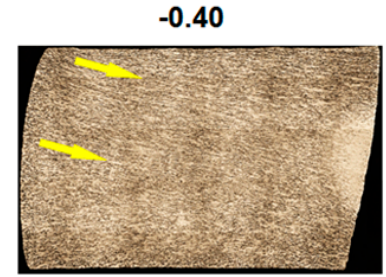

$\underline{2 m m}$

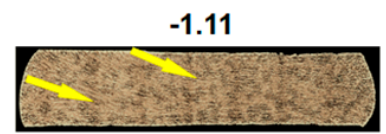

$\underline{2 m m}$

Figure 2. Interrupted hot compression tests of ZK30 samples conducted at $350{ }^{\circ} \mathrm{C}$ and $\dot{\varepsilon}$ of $10 \mathrm{~s}^{-1}$ : (a) experiments setup in the Gleeble system, (b) compressive true strain-stress curves with final strains of $-0.22,-0.40,-0.69$, and -1.11 , (c) pictures of ZK30 cylinders compressed to $\varepsilon_{t}$ of $-0.22,-0.40,-0.69$, -1.11 , and (d) corresponding macro-structures with yellow arrows marking the boundaries of shear bands (the samples were cross sectioned transversely along the centerline).

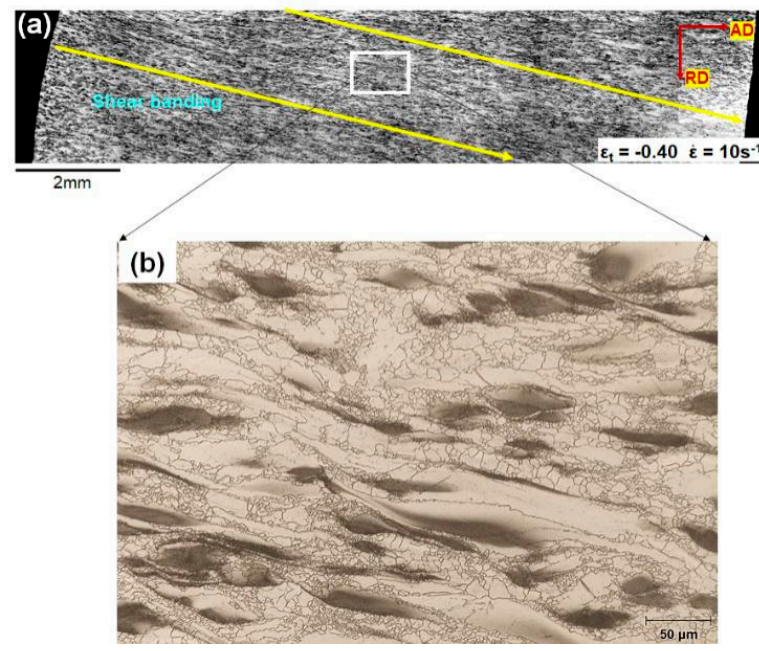

Figure 3. Optical micrographs of macro-SBs at $\varepsilon_{t}$ of -0.40 under the high-strain-rate condition: (a) overall microstructure at a lower magnification, (b) microstructure in the framed region of (a) at a higher magnification. 


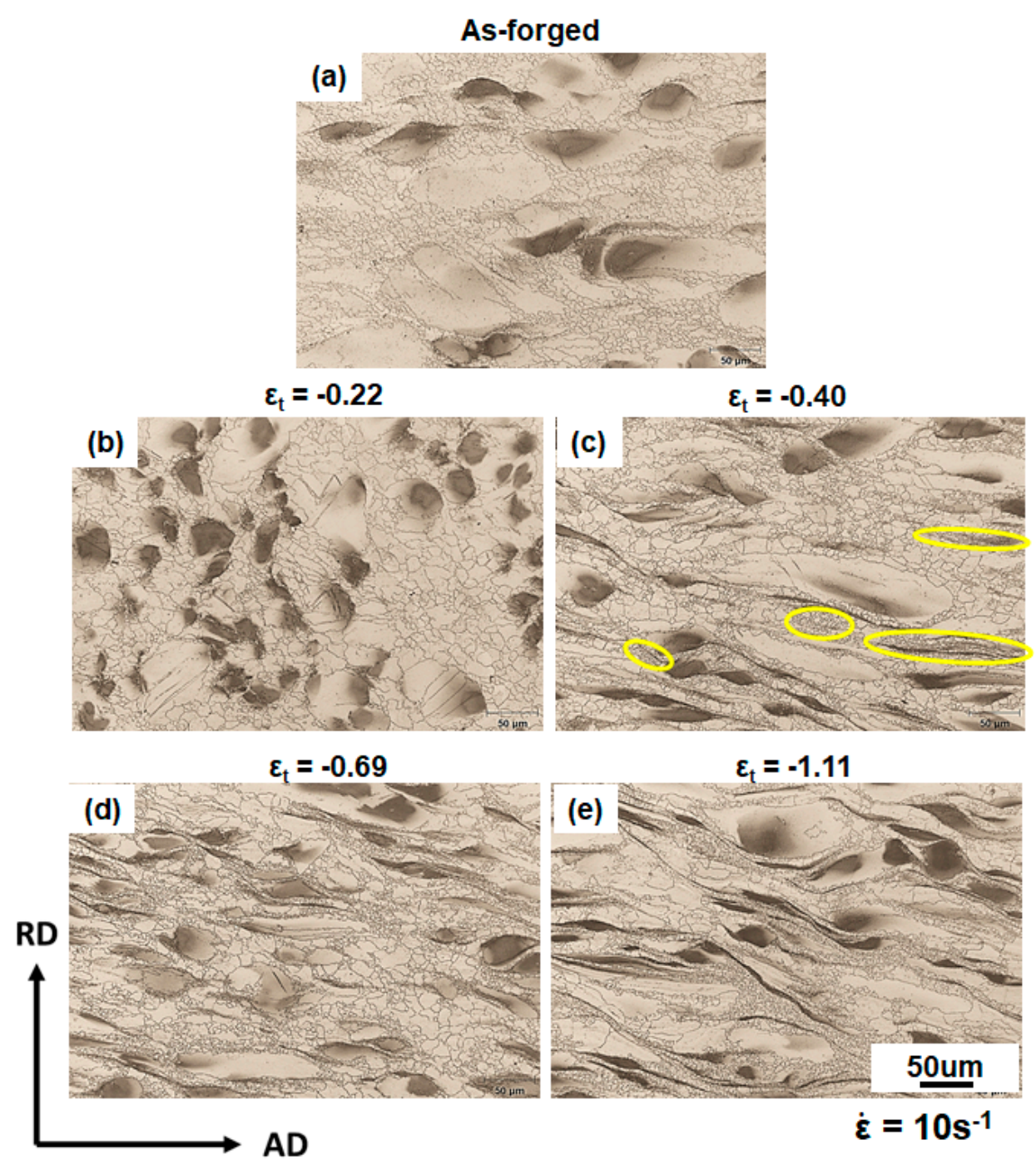

Figure 4. Optical micrograph of microstructures after compression with $\varepsilon_{\mathrm{t}}$ of (a) 0 , (b) -0.22 , (c) -0.40 (d) -0.69 , and (e) -1.11 at $350{ }^{\circ} \mathrm{C}$ and $10 \mathrm{~s}^{-1}$. Yellow ellipses highlight refined DRXed grains formed near the Zr-rich coarse grains.

Figure 5 shows the comparison of the microstructures of the samples hot compressed to $\varepsilon_{\mathrm{t}}$ of -0.40 and -1.11 at different strain rates of $10 \mathrm{~s}^{-1}$ and $10^{-3} \mathrm{~s}^{-1}$, respectively. Distinct deformation behaviors influenced by strain rates were implied from the microstructural observations. Different from the sample deformed to $\varepsilon_{\mathrm{t}}$ of -0.40 at $\dot{\varepsilon}$ of $10 \mathrm{~s}^{-1}$ (Figure $5 \mathrm{~b}$ ), the sample deformed to the same strain level at $\dot{\varepsilon}$ of $10^{-3} \mathrm{~s}^{-1}$ showed a relatively homogeneous grain size distribution, and no abnormal grain growth was observed (Figure $5 \mathrm{c}$ ). In addition, at $\varepsilon_{\mathrm{t}}$ of -1.11 , nearly all the coarse grains were consumed by DRXed grains under the quasi-static condition (Figure 5e), whereas a certain fraction of the Zr-lean coarse grains remained under the high-strain-rate condition (Figure $5 \mathrm{~d}$ ). This is likely due to the fact that DRX kinetics decrease with increasing strain rate. 


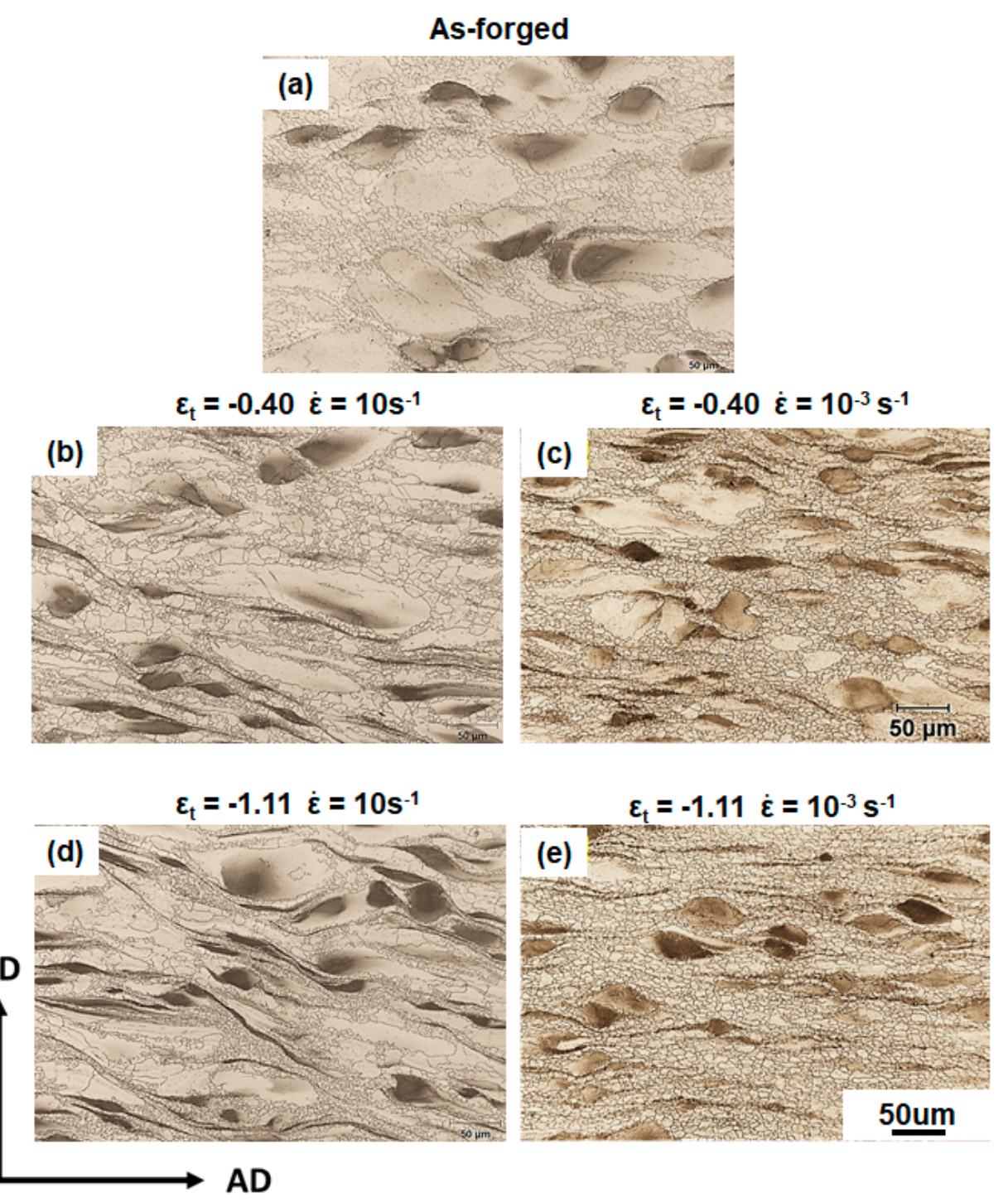

Figure 5. Optical micrographs of microstructures in different states: (a) as-forged state, after deformation at $\dot{\varepsilon}$ of $10 \mathrm{~s}^{-1}$ with $\varepsilon_{\mathrm{t}}$ of $(\mathbf{b})-0.40$ and (d) -1.11 , after deformation at $\dot{\varepsilon}$ of $10^{-3} \mathrm{~s}^{-1}$ with $\varepsilon_{\mathrm{t}}$ of (c) -0.40 and $(\mathbf{e})-1.11$.

\subsection{EBSD Characterizations of the Compressed Microstructures}

\subsubsection{Grain Average Misorientation Analysis of Global Microstructures}

Region of interests (ROIs) for EBSD characterization were all from the center of the macro-SBs of the tested samples. Figure 6a shows the IPF maps for the samples deformed with $\varepsilon_{t}$ of $-0.22,-0.40$, and -1.11 at $\dot{\varepsilon}$ of $10 \mathrm{~s}^{-1}$. Grain reconstruction for EBSD datasets was performed, based on the threshold misorientation angle of $5^{\circ}$ between neighbor measurements. Grain boundaries were plotted as black solid lines in Figure 6a. The IPF maps confirmed the OM observation that extensive grain growth occurred at $\varepsilon_{t}$ of -0.22 and -0.40 while profuse grain refinement occurred at $\varepsilon_{t}$ of -1.11 for the samples hot deformed at the high strain rate, in comparison to the initial microstructure (Figure 1c).

Grain-averaged band contrast (GBC) maps superimposed with boundaries are shown in Figure $6 \mathrm{~b}$. Low-angle grain boundaries (LAGBs) are defined as misorientation segments in the range of $5-15^{\circ}$. High-angle grain boundaries are the misorientation segments $>15^{\circ}$. Twin boundaries were identified as misorientation segments within a tolerance of $5^{\circ}$ from the characteristic values (extension twinning of $86.3^{\circ}$, contraction twinning of $56^{\circ}$, and double twinning of $37.5^{\circ}$ ). The band contrast value reveals the quality of EBSD patterns. Higher grayscale intensity in band contrast indicates a lower quality of 
the EBSD pattern. Mean band contrast was calculated for each grain to plot the GBC map. Combining Figure $6 b, d$, it is found that $\mathrm{Zr}$-rich domains corresponded to the dark-gray contrasted regions in the GBC maps. Since the quality of the EBSD pattern is significantly degraded by the lattice defects generated in plastic deformations, higher grayscale intensity in the GBC map indicates increased plastic strain [26,27]. It is thereby inferred that more deformation defects were trapped in the $\mathrm{Zr}$-rich domains. It is noted that only a limited fraction of twin boundaries could be observed during the hot deformation.

(a)

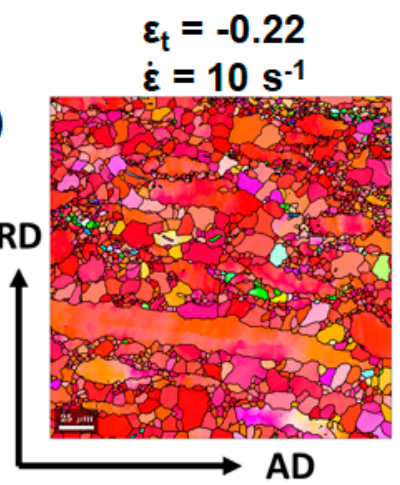

(b)

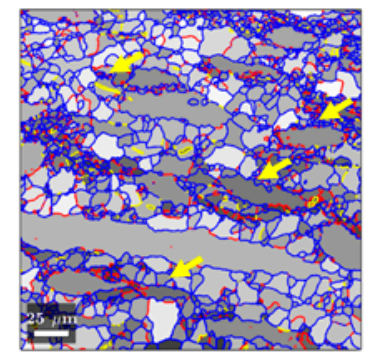

(c)

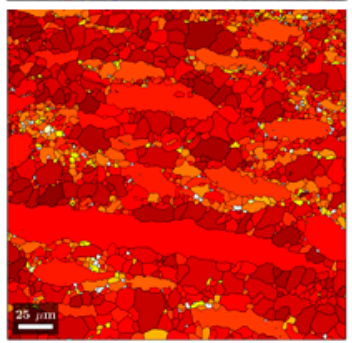

(d)

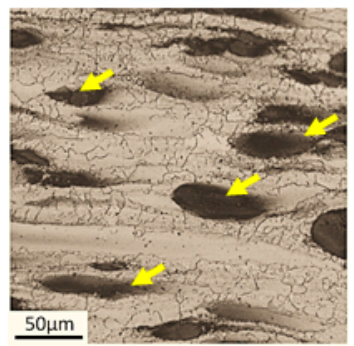

$$
\varepsilon_{\mathrm{t}}=-\mathbf{0 . 4 0}
$$$$
\dot{\varepsilon}=10 \mathrm{~s}^{-1}
$$
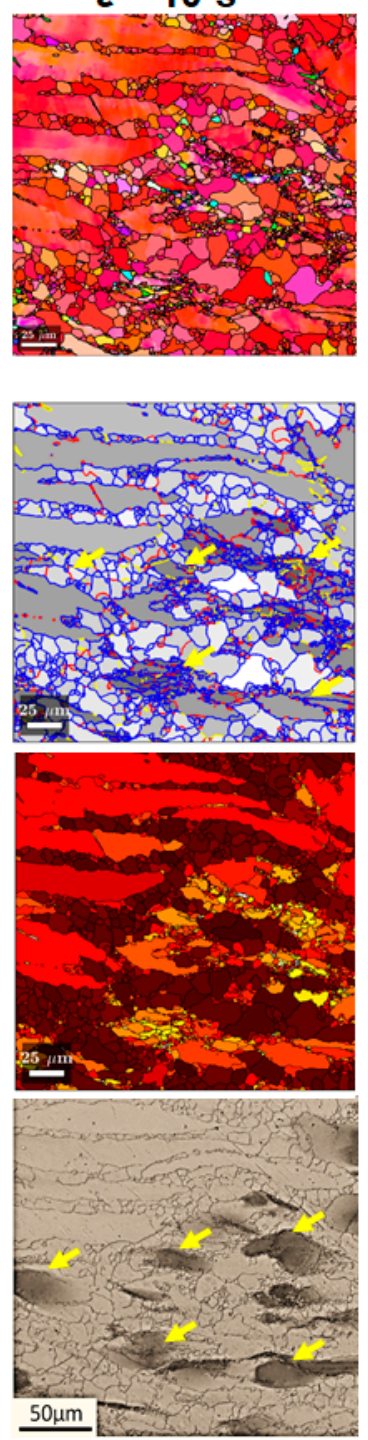
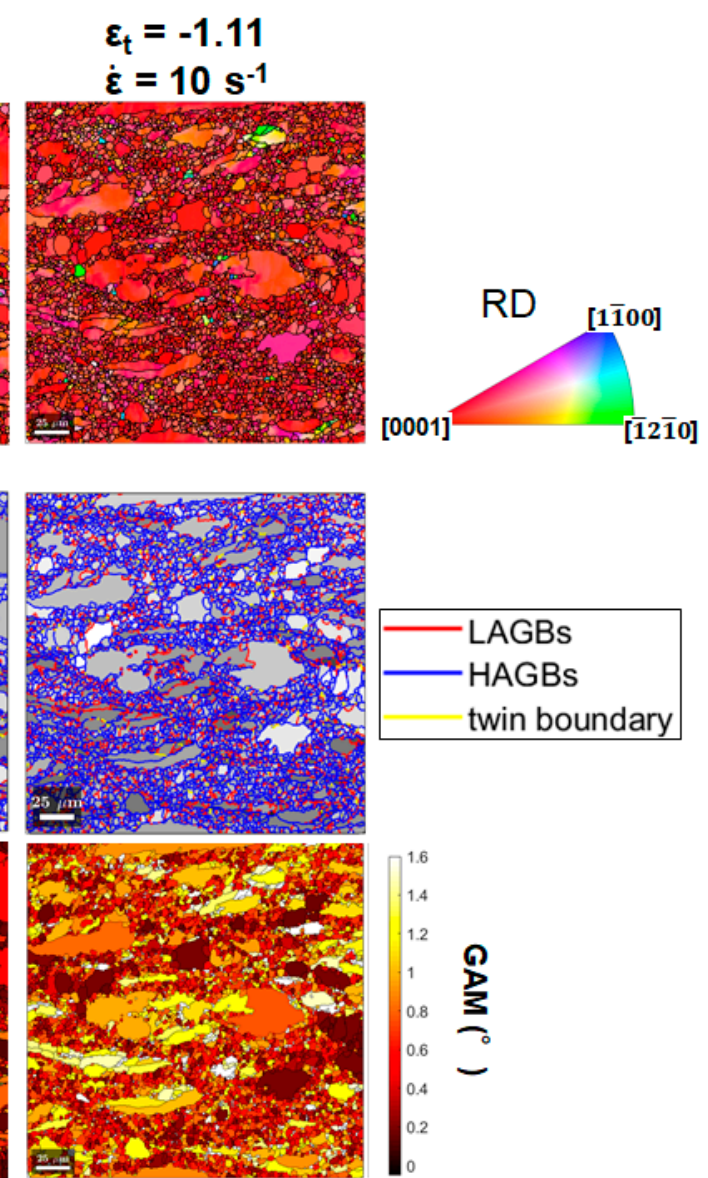

Figure 6. EBSD characterization of the microstructures deformed to $\varepsilon_{t}$ of $-0.22,-0.40,-1.11$ at $10 \mathrm{~s}^{-1}$ : (a) IPF maps and (b) GBC maps superimposed by grain boundaries, (c) GAM maps and (d) corresponding optical micrographs for the same ROIs. The step size for EBSD measurements was $0.3 \mu \mathrm{m}$. Yellow arrows indicate that dark-grey contrasted region in (b) correspond to Zr-rich domains in (d).

Similar to GBC, grain average misorientation (GAM) has a linear correlation with the plastic strain level and is often used to quantify plastic deformation $[28,29]$. To begin with, the kernel average misorientation (KAM), as a measure of local misorientation [27-29], can be derived from EBSD measurements. For each pixel, KAM calculates the average misorientation angles between it and its neighboring pixels. Then, GAM can be derived for individual grains by averaging the KAM 
values of all the pixels in the grain. GAM maps in Figure $6 c$ for the same regions in Figure $6 a, b$ were plotted to reveal the deformation behavior of the ZK30 alloy. The grown equiaxed grains, which are lean in Zr content, showed relatively low GAM values in the microstructures. It is speculated that their occurrence is closely related to recrystallization. In addition, the fraction of domains of GAM value $>1.0^{\circ}$ increased as deformation continued. In correlation with the corresponding OM images in Figure 6d, it seems that the domains of high GAM values roughly correspond to $\mathrm{Zr-rich}$ domains. Since the GAM value has a linear correlation with plastic strain, the results suggest that Zr-rich coarse grains undertook a significant proportion of the plastic strain during hot deformations.

GAM maps for as-forged, high-strain-rate deformed, and low-strain-rate deformed microstructures are shown in Figure $7 \mathrm{a}-\mathrm{c}$, respectively. For a given strain level, GAM distribution seemed to be more inhomogeneous for the microstructure deformed at $\dot{\varepsilon}$ of $10 \mathrm{~s}^{-1}$. The corresponding plots of grain size versus the GAM value were constructed for individual conditions (Figure 7d-f). After being deformed to $\varepsilon_{\mathrm{t}}$ of -0.40 under the quasi-static condition, the distribution of GAM values (Figure 7e) moved toward a slightly higher value globally but retained a similar shape as that in the as-forged state (Figure 7d). However, the plot for the microstructure deformed to $\varepsilon_{\mathrm{t}}$ of -0.40 at $\dot{\varepsilon}$ of $10 \mathrm{~s}^{-1}$ (Figure 7f) shows a distinct shape owing to the occurrence of a certain fraction of grown equiaxed grains of grain size $>10 \mu \mathrm{m}$ and low GAM values $<0.35^{\circ}$. The grown equiaxed grains featured by GAM value $<0.35^{\circ}$ were visualized in dark-gray color code in the partitioned GAM maps in Figure 8.

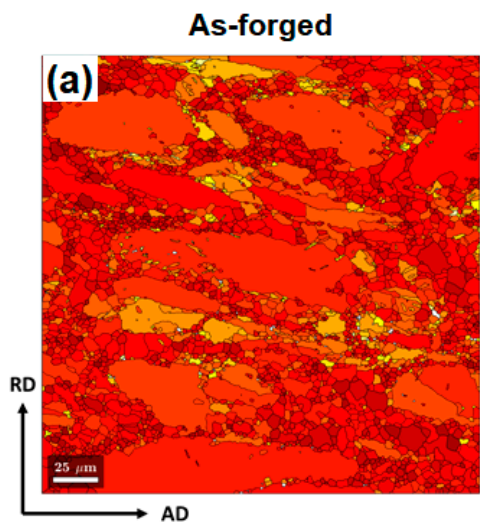

(d)

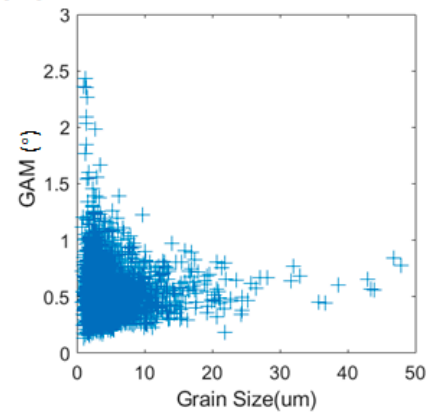

$\varepsilon_{\mathrm{t}}=-0.22 \dot{\varepsilon}=10^{-3} \mathrm{~s}^{-1}$

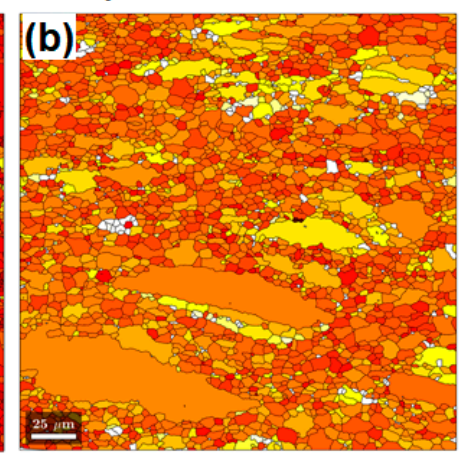

(e)

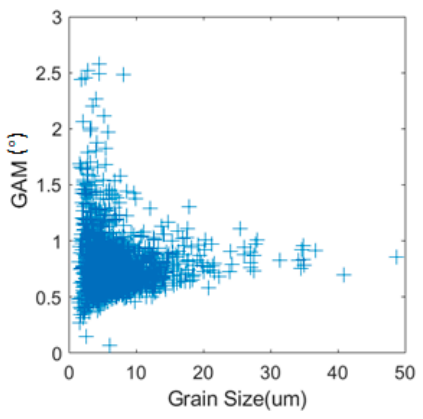

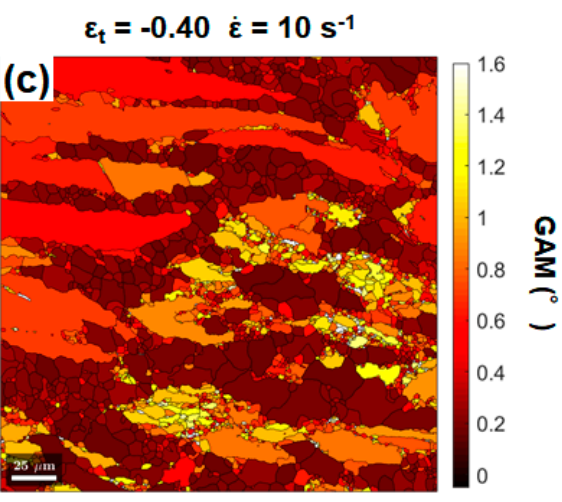

(f)

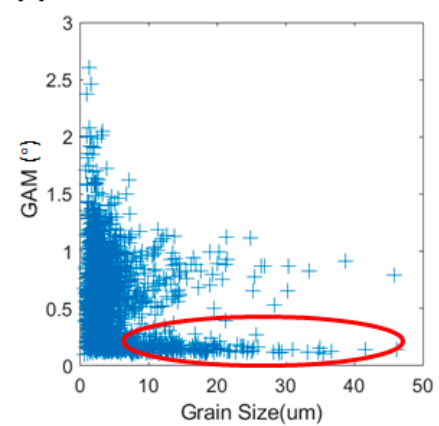

Figure 7. GAM maps for the microstructures in: (a) the as-forged state, deformed state with $\varepsilon_{\mathrm{t}}$ of -0.40 (b) at $\dot{\varepsilon}$ of $10 \mathrm{~s}^{-1}$ and (c) at $\dot{\varepsilon}$ of $10^{-3} \mathrm{~s}^{-1}$. The corresponding plots of grain size versus the GAM value are plotted in $(\mathbf{d}-\mathbf{f})$. The yellow ellipse in (f) highlights the occurrence of grown equiaxed grains with low GAM value and large grain size. 


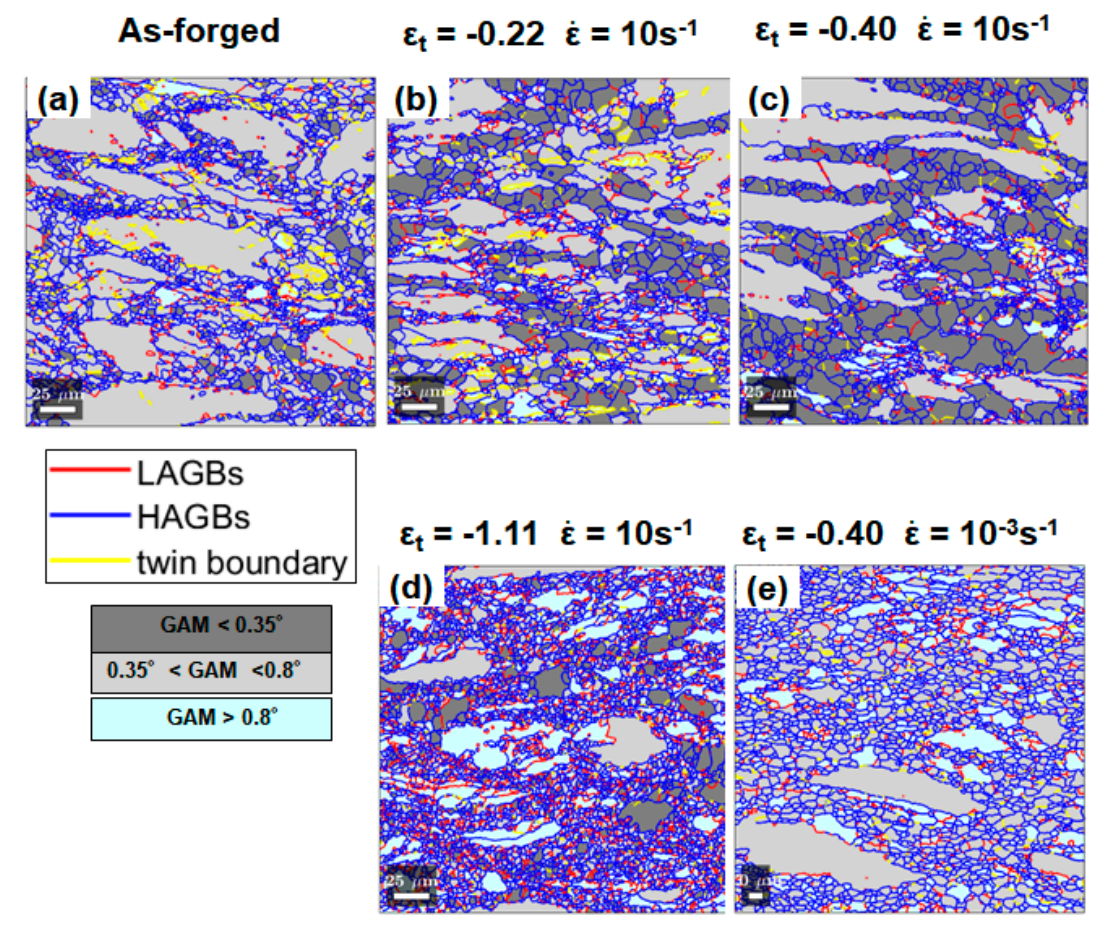

Figure 8. Partitioned GAM maps with threshold values of $0.35^{\circ}$ and $0.8^{\circ}$ for the microstructures in: (a) as-forged state, deformed state (b) with $\varepsilon_{\mathrm{t}}$ of -0.22 at $\dot{\varepsilon}$ of $10 \mathrm{~s}^{-1}$, (c) with $\varepsilon_{\mathrm{t}}$ of -0.40 at $\dot{\varepsilon}$ of $10 \mathrm{~s}^{-1}$, (d) with $\varepsilon_{\mathrm{t}}$ of -1.11 at $\dot{\varepsilon}$ of $10 \mathrm{~s}^{-1}$, and (e) with $\varepsilon_{\mathrm{t}}$ of -0.40 at $\dot{\varepsilon}$ of $10^{-3} \mathrm{~s}^{-1}$.

\subsubsection{Texture and Misorientation Analysis of Different Groups of Grains}

To further analyze the microstructural evolution during the hot compression at $\dot{\varepsilon}$ of $10 \mathrm{~s}^{-1}$, certain threshold values were set for the GAM value and grain size to partition grains into different groups based on correlated OM images and EBSD datasets. Figure 9 shows a typical example of this approach for the microstructure at $\varepsilon_{t}$ of -0.40 . The grains with a GAM value $>0.35^{\circ}$ and grain size $<10 \mu \mathrm{m}$, represented by red symbols in Figure $9 \mathrm{~b}$, correspond to the refined grains with IPF color code in Figure 9c. In combination with the OM image in Figure 9a, this group of grains can be approximately referred to refined grains formed within or in the vicinity of Zr-rich coarse grains. It is thereby assumed that this group of grains resulted from the partial DRX of Zr-rich coarse grains. Grains corresponding to green symbols, in the range of the GAM value $<0.35^{\circ}$ and grain size $<10 \mu \mathrm{m}$ in Figure 9b, are shown in Figure 9d. They can roughly represent the fine DRXed grains lean in $\mathrm{Zr}$ in Figure 9a. The grown equiaxed grains in Figure $9 \mathrm{e}$ are mainly captured by blue symbols in the range of the GAM value $<0.35^{\circ}$ and grain size $>10 \mu \mathrm{m}$. Lastly, grains represented by cyan symbols are the sheared coarse grains including both Zr-rich and Zr-lean ones, as shown in Figure 9f. Using this grain partition approach based on GAM and grain size, complicated microstructures in the deformed samples were partitioned to trace the evolution of varied groups of grains.

The $\{0001\}$ pole figures for these groups of grains are plotted in Figure 10. Figure 10d shows that the $\{0001\}$ poles of the coarse grains (cyan group) in the samples hot deformed at $\dot{\varepsilon}$ of $10 \mathrm{~s}^{-1}$ were more concentrated to the RD than the initial coarse grains in the as-forged state. This was likely caused by the profuse operation of basal slip in the coarse grains whose c-axes initially tilted away from the RD. Figure 10b-d suggest that the refined DRXed grains (red group and green group) and the grown equiaxed grains (blue group) showed a texture similar to the sheared coarse grains after deformation. It is noted that no texture randomization occurred during the hot deformations. In general, twinning-induced DRX (TDRX) and conventional discontinuous DRX (DDRX) tended to weaken the initial texture by producing DRXed grains of randomized orientations. It is thereby inferred that TDRX and conventional DDRX were not the dominant DRX mechanisms. 
(a)
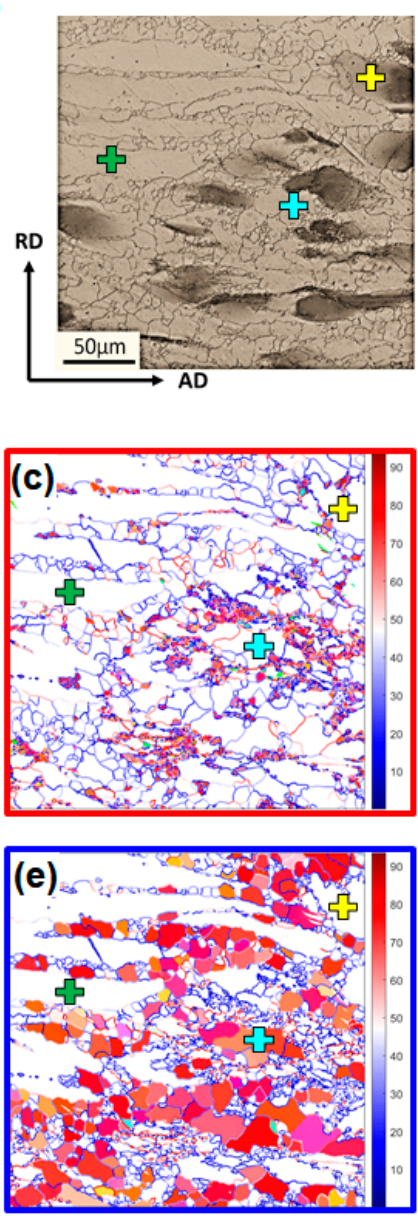

(b)
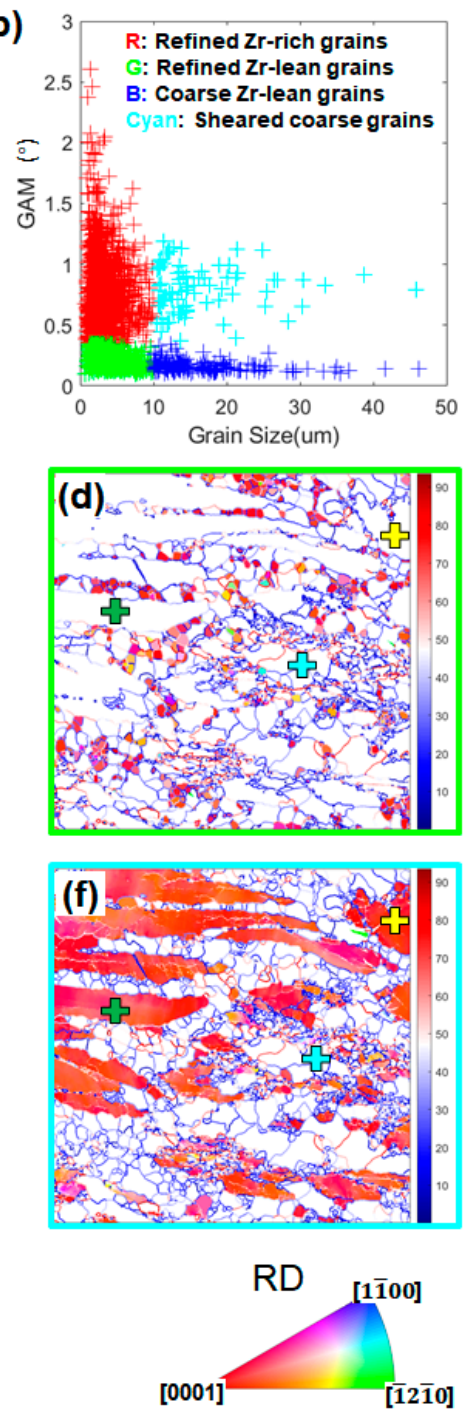

Figure 9. Grain partition approach based on the EBSD map for the sample deformed to a true strain of -0.69 at $10 \mathrm{~s}^{-1}$ : (a) optical micrograph of the ROI, (b) plot of grain size versus GAM value for all the grains in the ROI. Grains were partitioned on a basis of both the GAM value (threshold value $=0.35^{\circ}$ ) and grain size (threshold value $=10 \mu \mathrm{m}$ ). Four groups are represented by red/green/blue/cyan color schemes. IPF maps for the same ROI in (a) showing (c) Zr-rich refined grains as the red group, (d) Zr-lean refined grains as the green group, (e) Zr-lean grown equiaxed grains as the blue group, and (f) sheared coarse grains as the cyan group. (The crosses on a and $c-f$ are for the reader to position feature grains for correlation).

Figure 11 shows the histograms for the GAM distribution of in the compressed samples, derived from Figure 6c. The sample compressed to $\varepsilon_{t}$ of -0.44 under the quasi-static condition (Figure $11 \mathrm{a}_{2}$ ) showed a similar GAM distribution to that of the as-forged sample (Figure 11 $\mathrm{a}_{1}$ ). In contrast, the fraction of grains at a high GAM value evidently increased in the high-strain-rate deformed samples, as shown in the histograms of Figure $11 a_{3-5}$. Figure $11 b_{1-5}$ show the GAM distribution of sheared coarse grains (cyan group in Figure 9). A comparison of Figures $11 b_{1}$ and $11 b_{3-5}$ reveals that both the fraction of the coarse grains with a GAM value $>1.0^{\circ}$ and the maximum GAM value increase with straining. This suggests that coarse grains gradually undertook more plastic strains with the deformation proceeding at $\dot{\varepsilon}$ of $10 \mathrm{~s}^{-1}$. In addition, a comparison of Figures $11 \mathrm{~b}_{2}$ and $11 b_{4}$ indicates that for a given strain level, more plastic strains localized in coarse grains at a high 
strain rate. This quantitative analysis supplements and supports the microstructural observations in Figures 7 and 8 .
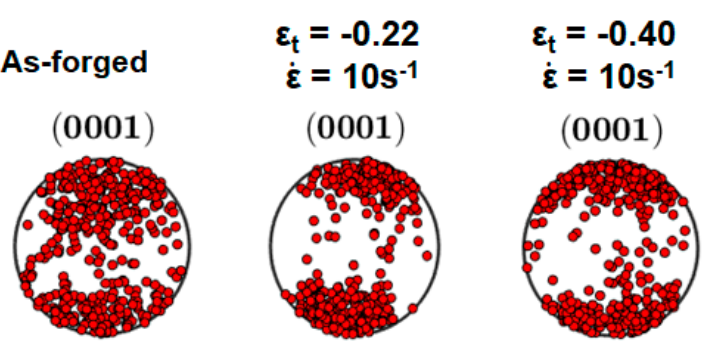

$$
\begin{aligned}
\varepsilon_{\mathrm{t}} & =-1.11 \\
\dot{\varepsilon} & =10 \mathrm{~s}^{-1}
\end{aligned}
$$

(a)
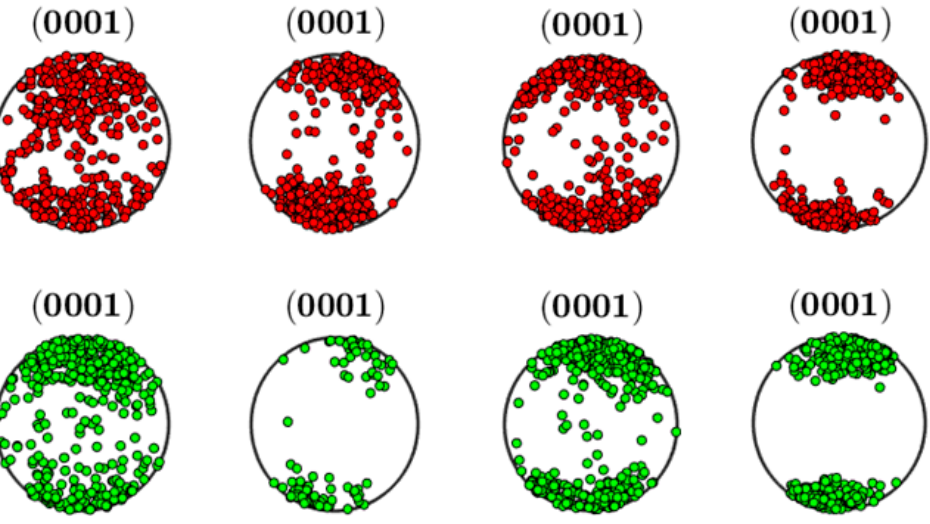

(b)
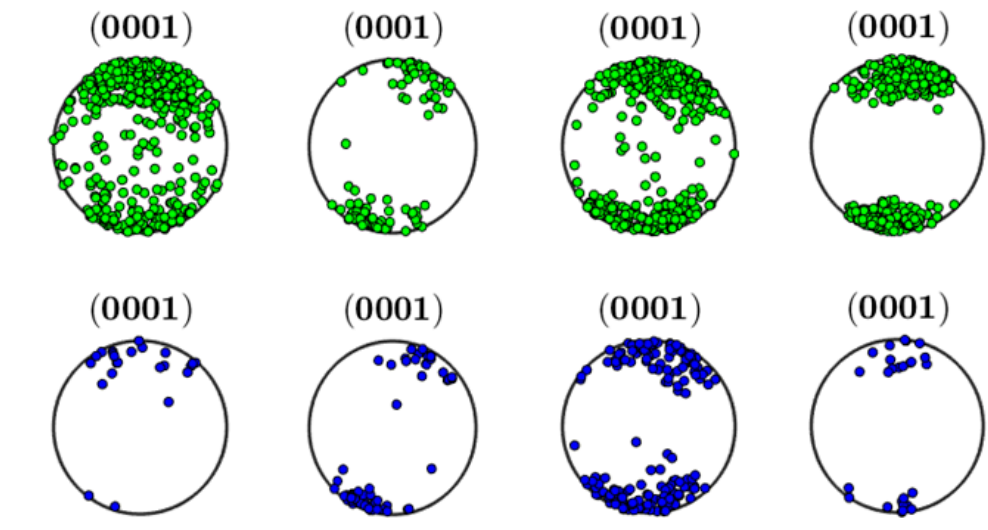

(c)

(0001)
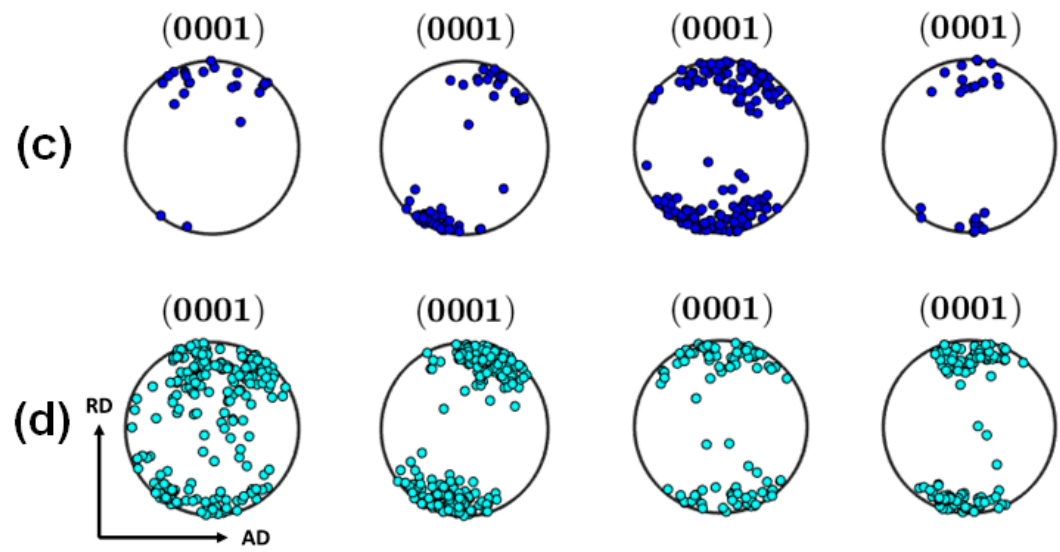

Figure 10. $\{0001\}$ pole figures of four groups of grains: (a) Zr-rich refined grains as the red group, (b) Zr-lean refined grains as the green group, (c) Zr-lean grown equiaxed grains as the blue group and (d) sheared coarse grains as the cyan group.
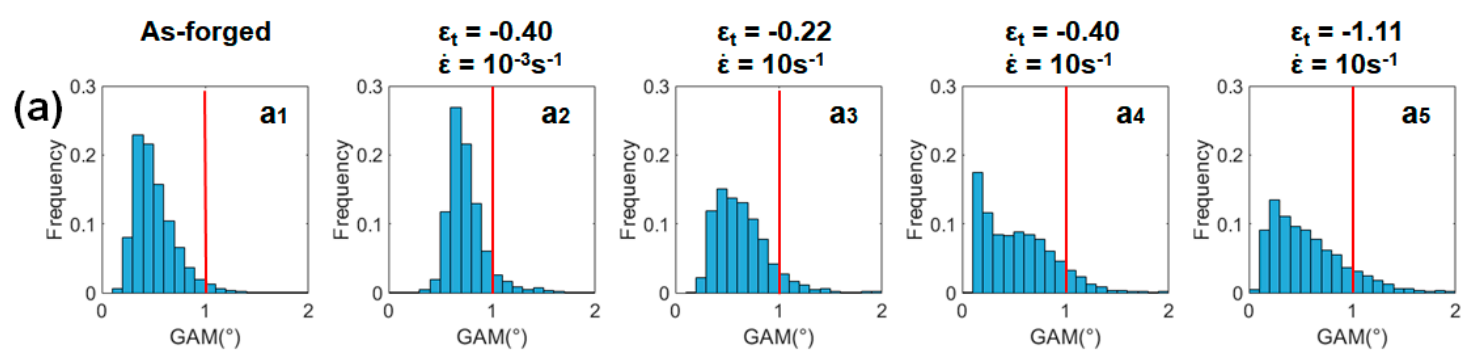

(b)
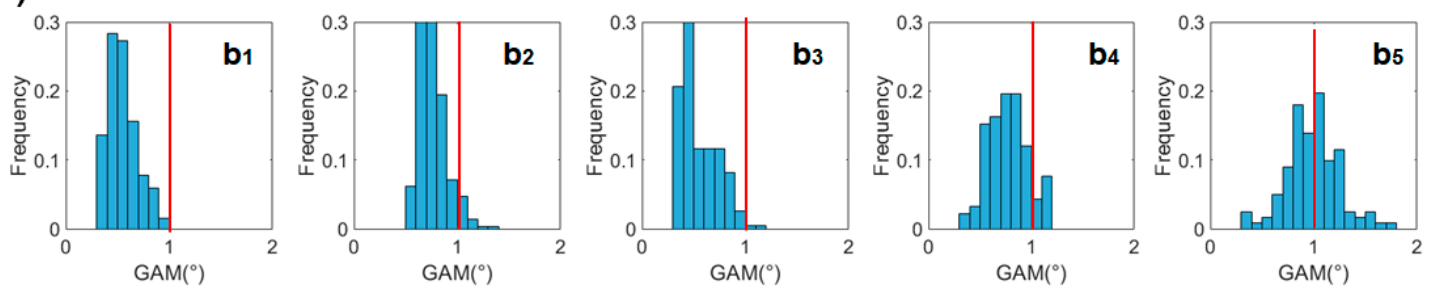

Figure 11. GAM histogram plots derived from EBSD data for: (a) all grains and (b) sheared coarse grains as the cyan group under varied conditions including the as-forged state, deformed states with $\varepsilon_{\mathrm{t}}$ of -0.22 at $10^{-3} \mathrm{~s}^{-1}$ and with $\varepsilon_{\mathrm{t}}$ of $-0.22,-0.40$ and -1.11 at $10 \mathrm{~s}^{-1}$. 


\subsubsection{Analysis of the Deformation/DRX Mechanisms of Zr-Rich Coarse Grains}

Attention has been paid to $\mathrm{Zr}$-rich domains for understanding the dominant DRX mechanisms operating during the hot deformations under a high-strain-rate condition. Figure 12 shows EBSD measurements with a high spatial resolution of $0.2 \mu \mathrm{m}$ at an $\varepsilon_{\mathrm{t}}$ step size of -0.22 and $\dot{\varepsilon}$ of $10 \mathrm{~s}^{-1}$, focusing on the details of a Zr-rich coarse grain. Abundant refined sub-grains bounded by LAGBs were observed in the vicinity of the boundaries of the coarse grain, as marked by yellow ellipses in Figure 12a. With further straining, these sub-grains will be transformed into DRXed grains via progressive rotation. This is consistent with the typical CDRX mechanism reported in previous studies [12,30,31]. In addition, bulging of initial grain boundaries with serrated morphologies was observed as marked by the white ellipse in Figure 12a. Some refined grains formed along the serrated boundaries as indicated by black arrows. They may be formed by bridging the corrugated boundaries by LAGBs which can be transformed into HAGBs as the deformation continues. This DRX behavior is referred to as DDRX via grain boundary corrugation/bulging [32,33]. It is noted that the DRXed grains formed by CDRX or DDRX via grain boundary corrugation/bulging tend to have orientations similar to the parent grains [34,35]. The grain reference orientation deviation (GROD) map [29,36] for $\alpha-\mathrm{Mg}$ grains is shown in Figure 12b. It is suggested that the $\mathrm{Zr}$-rich coarse grain had substantial misorientations built up in the vicinity of boundaries, which supports the assumption that CDRX and DDRX were active in these regions [33]. The in-grain misorientation axes (IGMA) analysis of the coarse grain in Figure 12c revealed that the corresponding Taylor axis for the dominant slip systems activated in the coarse grain was $<0001>[31,37-39]$. The activated $<0001>$ slip systems indicated high activity of the prismatic slip in the grain. In general, activation of non-basal slip is necessary for CDRX to be active in Mg alloys [33,40].

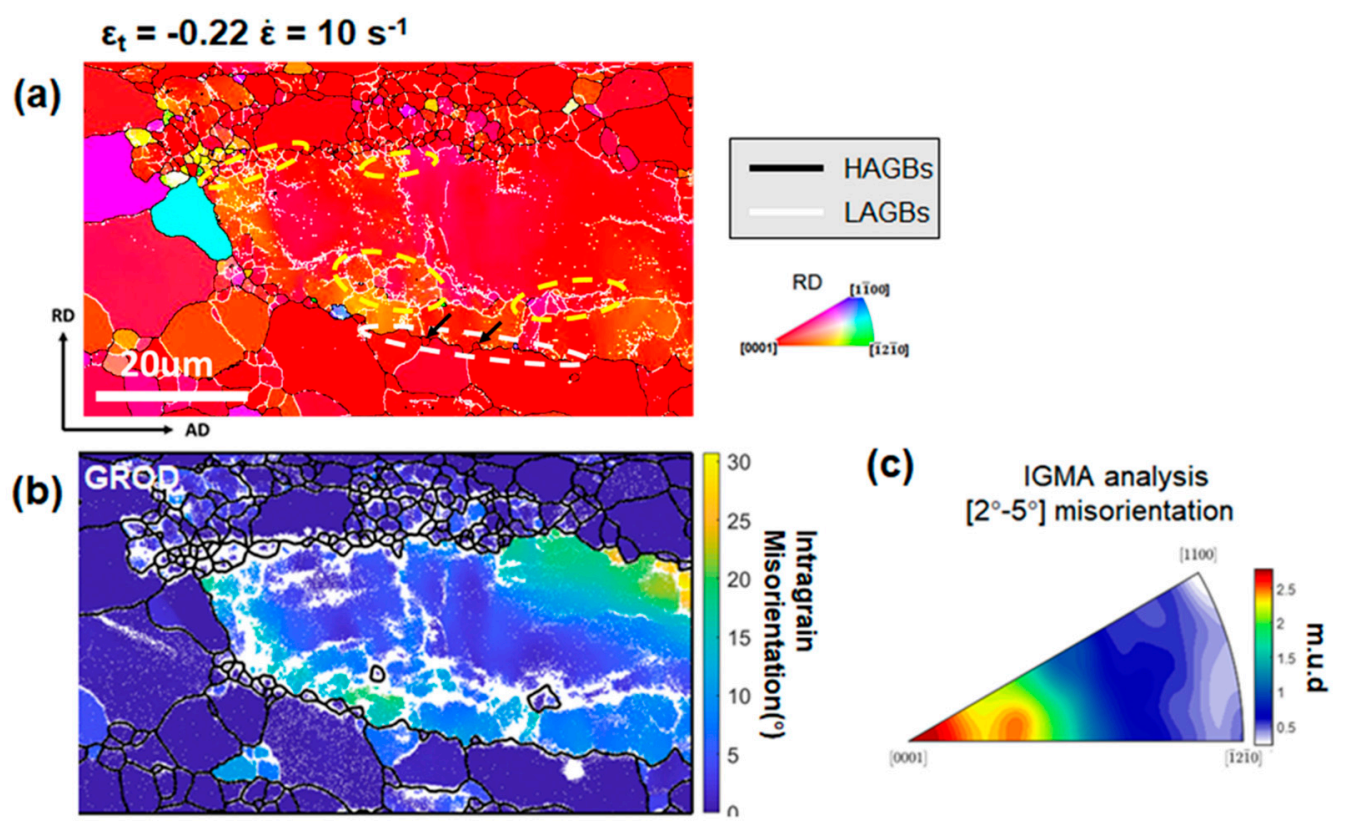

Figure 12. (a) IPF map of the microstructure deformed to $\varepsilon_{t}$ of -0.22 at $\dot{\varepsilon}$ of $10 \mathrm{~s}^{-1}$ with a step size of $0.12 \mu \mathrm{m}$, with sub-grains marked by yellow ellipses, serrated boundaries marked by a white ellipse, and refined DRXed grains marked by black arrows. (b) GROD map calculated from (a), and (c) IGMA analysis of the coarse grain shown in (b).

Figure 13a shows the IPF map superimposed with grain boundaries from an EBSD dataset at $\varepsilon_{t}$ of -0.69 at $\dot{\varepsilon}$ of $10 \mathrm{~s}^{-1}$, with a step size $0.12 \mu \mathrm{m}$. Based on the grain partition approach elaborated in the Section 3.3.2, grains in Figure 13a were differentiated into four groups and colored in Figure 13b. Zr-rich domains, including Zr-rich coarse grains (cyan colored), and Zr-rich DRXed grains (red colored) around the coarse grains, were identified. Correlating Figure 13b with Figure 13a, sub-grains bounded 
by LAGBs as indicated by white arrows and grain boundary corrugations as indicated by black arrows were observed in the vicinity of the boundaries of Zr-rich coarse grains. The Zr-rich DRXed grains (red group) may have evolved from these sub-grains. This confirms that CDRX and DDRX via grain boundary corrugation/bulging were dominant in the DRX process of Zr-rich coarse grains. The corresponding mean GROD map for the same region is shown in Figure 13c. IGMA analysis (Figure 13d) of the coarse grain of the highest average GROD value, which is marked by ' $a$ ' in Figure 13c, indicates that the corresponding Taylor axes for the dominant slip systems activated in the coarse grain were $<0001>$ and $<1 \overline{1} 00>[31,37-39]$. It is inferred that the co-activation of basal slip and prismatic slip contributed to the accommodation of plastic strains and the DRX process.

(a)

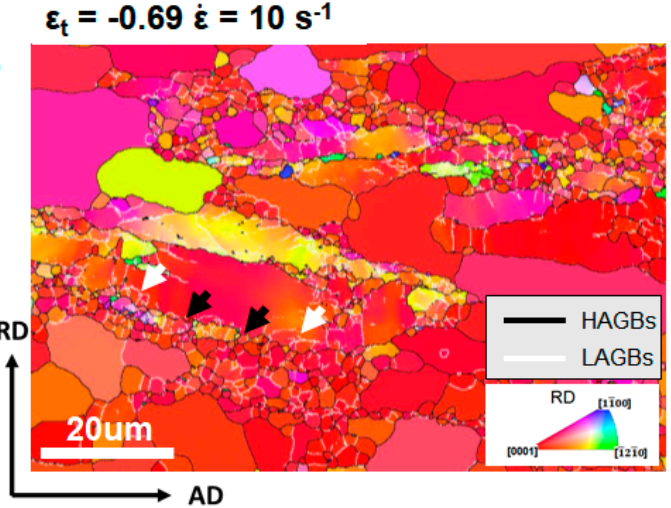

(c)

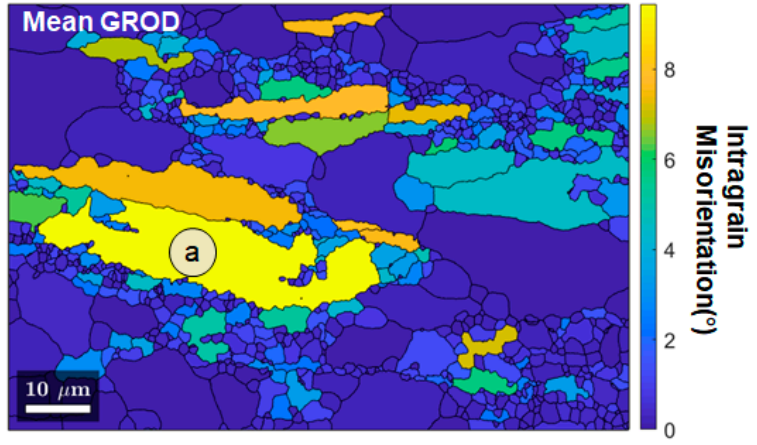

(b)
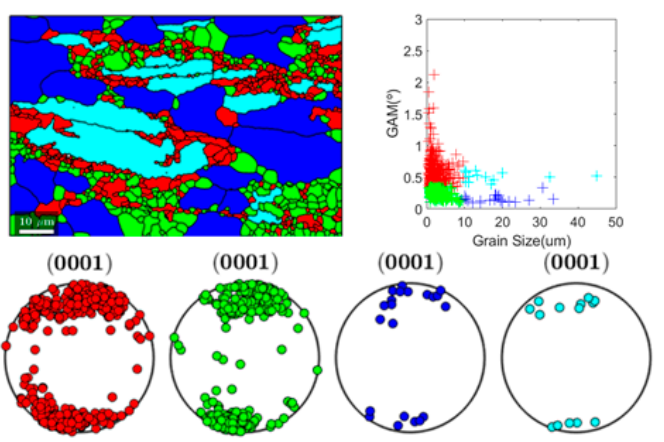

(d)

IGMA analysis $\left[2^{\circ}-5^{\circ}\right]$ misorientation

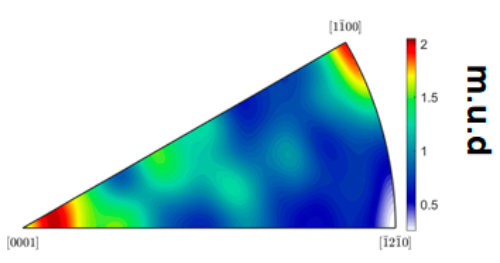

Figure 13. (a) IPF map of the microstructure deformed to $\varepsilon_{t}$ of -0.69 at $\dot{\varepsilon}$ of $10 \mathrm{~s}^{-1}$ with a step size of $0.12 \mu \mathrm{m}$. White arrows indicate sub-grains, and black arrows indicate grain boundary corrugations. (b) Grain partitioning map on the basis of the GAM value and grain size. Grains were divided into a $\mathrm{red} /$ green/blue/cyan color scheme with the corresponding pole figures shown at the bottom, (c) mean GROD map, (d) IGMA analysis of the sheared coarse grain labeled 'a' in (c).

\section{Discussion}

\subsection{Post-DRX (PDRX) after the Hot Compression}

The growth of Zr-lean equiaxed grains occurred in the microstructures of the samples hot compressed at $\dot{\varepsilon}$ of $10 \mathrm{~s}^{-1}$ (Figures 4 and 6). All the experimental results presented suggest that this was caused by post-DRX (PDRX) after the hot compression ceased, supported by the following:

(1) For a given strain level of -0.40 , the size of the grown equiaxed grains in the sample deformed at $\dot{\varepsilon}$ of $10 \mathrm{~s}^{-1}$ was larger than the DRXed grains in the sample deformed at $\dot{\varepsilon}$ of $10^{-3} \mathrm{~s}^{-1}$ (Figure 7). In terms of a well-established theory that a higher strain rate leads to finer DRXed grains, it is unlikely that the grown equiaxed grains were produced during the high-strain-rate deformation. Moreover, the GAM values of the grown equiaxed grains at $\dot{\varepsilon}$ of $10 \mathrm{~s}^{-1}$ (Figure 7c) were lower than those of the DRXed grains at $\dot{\varepsilon}$ of $10^{-3} \mathrm{~s}^{-1}$ (Figure $7 \mathrm{~b}$ ). Therefore, it is reasonable to believe that the grown equiaxed grains were from static recrystallization (SRX) after the hot deformation ceased, 
owing to the quench delay in the present study. The growth of DRXed nucleus probably happened in the interval between the end of compression and water quenching $(\sim 4-5 \mathrm{~s})$. Considering that DRX softening was initiated at the true strain of -0.17 (Figure $2 b$ ), the equiaxed grains with large size were more likely from the growth of the DRX nucleus produced during the hot compression. This is consistent with the phenomenon of meta-dynamic recrystallization (MDRX) [41-43], which is a type of PDRX. MDRX tends to be triggered during hot deformation conducted at a high strain rate. Dislocation density and stored strain energy increase with strain rate at a given temperature and for a given strain level, which provides the driving force for the growth of the DRXed nucleus [44].

(2) The fraction of the grown equiaxed grains with a GAM value $<0.35^{\circ}$ in the high-strain-rate deformed sample at $\varepsilon_{t}$ of -1.11 (Figure $8 \mathrm{~d}$ ) was much lower than that of the samples deformed under the same condition but at lower strains (Figure 8b,c). Stored strain energy was released via DRX in the sample deformed to $\varepsilon_{t}$ of -1.11 . Therefore, the driving force for PDRX/MDRX was significantly reduced.

(3) The grown equiaxed grains existed in the Zr-lean domains while the grains residing in the Zr-rich domains retained a refined size. The dispersion of $Z n-Z r$ precipitates retarded grain boundary migration; thereby, the growth of the DRX nucleus formed in the Zr-rich domains was impeded. Therefore, the PDRX phenomenon could only be observed in the Zr-lean domains.

\subsection{Microstructural Evolution of ZK30 during Hot Compression}

Since the as-received material is of a bimodal microstructure from partial DRX, it is challenging to differentiate initial DRXed grains formed in forging from the DRXed grains produced in the hot compression. Moreover, the occurrence of PDRXed grains aggravates the difficulty in interpreting the microstructural evolution of the ZK30 alloy during the hot compression at $\dot{\varepsilon}$ of $10 \mathrm{~s}^{-1}$.

At $\varepsilon_{\mathrm{t}}$ of -0.22 , the DRX softening outweighed strain hardening as reflected by the decline of true stress beyond the peak in the corresponding stress-strain curve (Figure 2b). At this strain level, the plastic strain undertaken by initial coarse grains was not significant, and deformation was not concentrated to macro-SBs (Figures $2 \mathrm{c}$ and $4 \mathrm{~b}$ ). The DRXed nucleus probably first formed in the Zr-lean regions during the compression and grew into the matrix of highly stored strain energy after the compression ceased. It is noted that the grown equiaxed grains from PDRX roughly inherited the orientation of the matrix, referring to Figure 10. It is inferred that the original DRXed nucleus had similar orientations as its parent grain.

With the deformation proceeding to $\varepsilon_{\mathrm{t}}$ of -0.40 , strain was localized to macro-SBs (Figure 3). This is supported by Figure 11b showing that the GAM values of coarse grains in the samples deformed at $\dot{\varepsilon}$ of $10 \mathrm{~s}^{-1}$ underwent a marked increment with increased strain. Meanwhile, more Zr-rich refined DRXed grains formed near the coarse grains at $\varepsilon_{t}$ of -0.40 (Figure $4 \mathrm{c}$ ). The Zr-rich DRXed refined grains were produced via CDRX and DDRX via boundary bulging along the boundaries of coarse grains, as elaborated in the Section 3.3.3. In the latter stage of hot compressions at $\varepsilon_{t}$ of -0.69 and -1.11 , more stored strain energy was released by profuse DRX. Therefore, the fraction of PDRXed grains in the microstructure at $\varepsilon_{\mathrm{t}}$ of -1.11 was much lower than that in the microstructures at lower strain levels (Figure 8). In addition, coarse grains were gradually consumed by DRXed grains with straining (Figure 5).

\subsection{Plasticity of ZK30 during Hot Compression at $\dot{\varepsilon}$ of $10 \mathrm{~s}^{-1}$}

Although TDRX was suppressed in the as-forged ZK30 alloy in the hot compression at $\dot{\varepsilon}$ of $10 \mathrm{~s}^{-1}$, the ZK30 alloy still exhibited excellent plasticity in the present study. This can be attributed to the following: 
(1) Severe shear banding related to geometrical softening caused by the formation of compression twinning and double twinning in the basal-textured matrix was impeded. This is because twinning was suppressed due to the refined grain size and high testing temperature.

(2) The dominant DRX mechanisms operating in the present study were CDRX and DDRX via boundary corrugation (Figures 12 and 13). DRXed grains produced via these mechanisms tended to have similar orientations as their parent grains. Although they coalesced to form a necklace structure around the coarse grains, strains were not concentrated in the necklace structure to form shear bands. This is because the DRXed grains in the necklace structure had similar Schmid factors for slip as the parent grains.

(3) It is believed that Zr-rich coarse grains played an essential role in accommodating plastic strains during the hot compression at $\dot{\varepsilon}$ of $10 \mathrm{~s}^{-1}$. It was observed that coarse grains in the macro-SBs gradually undertook more plastic strain with straining. Since the distribution of $\mathrm{Zr}$-rich coarse grains was relatively homogeneous in the macro-SBs, deformation within the macro-SBs was homogenized and thereby, good plasticity of the as-forged ZK30 alloy was achieved. Referring to Figures 12 and 13, prismatic slip was activated in the Zr-rich coarse grains. Non-basal slip activity contributed to the operation of CDRX in the vicinity of Zr-rich coarse grains, leading to the relaxation of stress concentration at the interphase. In addition, the activated non-basal slip enhanced the plasticity of $\mathrm{Zr}$-rich coarse grains by providing more independent deformation mechanisms.

The high activity of prismatic slip in the Zr-rich coarse grains may be correlated with the reduction of the ratio of critical resolved shear stress (CRSS) of the prismatic slip to that of the basal slip. The reduced deformation anisotropy is believed to be caused by the dispersion of $\mathrm{Zn}-\mathrm{Zr}$ precipitates within the coarse grains. As shown in Figure 14 obtained from the sample deformed to $\varepsilon_{t}$ of -0.40 at $\dot{\varepsilon}$ of $10 \mathrm{~s}^{-1}, \mathrm{Zn}-\mathrm{Zr}$ precipitates observed in the $\mathrm{Zr}$-rich domains exhibited spherical morphology with the average equivalent diameter of $\sim 9.4 \mathrm{~nm}$ and showed a high number density. It is generally thought that $\mathrm{Zn}-\mathrm{Zr}$ particles dispersed in the matrix of $\mathrm{Mg}-\mathrm{Zn}-\mathrm{Zr}$ alloys do not have a marked contribution to the overall strength since they only form in a limited number of coarse grains with $\mathrm{Zr}$ segregation [45]. However, when it comes to individual coarse grains enriched in $\mathrm{Zn}-\mathrm{Zr}$ particles, the strengthening effect of the precipitates on basal and prismatic slips may be noticeable. Given that the strengthening effect of $\mathrm{Zn}-\mathrm{Zr}$ precipitates on the CRSS of basal and prismatic slips are $\Delta \tau_{\text {basal }}$ and $\Delta \tau_{\text {prism }}$, the ratio $C R S S_{\text {prim }} / C R S S_{\text {Basal }}$ will change to $\left(C R S S_{\text {prim }}+\Delta \tau_{\text {prism }}\right) /\left(C R S S_{\text {Basal }}+\Delta \tau_{\text {basal }}\right)$ when the effect of $\mathrm{Zn}-\mathrm{Zr}$ precipitates is accounted for. If $\Delta \tau_{\text {prism }} / \Delta \tau_{\text {basal }}<C R S S_{\text {prim }} / C R S S_{\text {Basal }}$, the ratio will be reduced, rendering prismatic slip more readily active. The ratio $C R S S_{\text {prim }} / C R S S_{\text {Basal }}$ of $\mathrm{Mg}$ alloys normally ranges from 2.5-7 [46,47]. Considering that the $\mathrm{Zn}-\mathrm{Zr}$ particles observed in this study showed spherical morphology, their strengthening effects on basal slip and prismatic slip is likely to be similar based on the Orowan bowing mechanism [48]. Therefore, it is reasonable to assume that the dispersion of $\mathrm{Zn}-\mathrm{Zr}$ precipitates in $\mathrm{Zr}$-rich coarse grains will reduce the ratio $C R S S_{\text {prim }} / C R S S_{\text {Basal }}$, leading to high activity of prismatic slip in the grains. Similar effects of precipitated $(\mathrm{Mg}, \mathrm{Al})_{2} \mathrm{Ca}$ particles in AZ31-0.5Ca alloy and G.P. zones in Mg-Al-Ca-Mn alloys on the reduced deformation anisotropy and enhanced plasticity of $\mathrm{Mg}$ alloys have been reported [49-51]. This study reveals that enhanced activity of non-basal slip is essential for the excellent plasticity of $\mathrm{Mg}$ alloys during deformation under a high-strain-rate condition. 

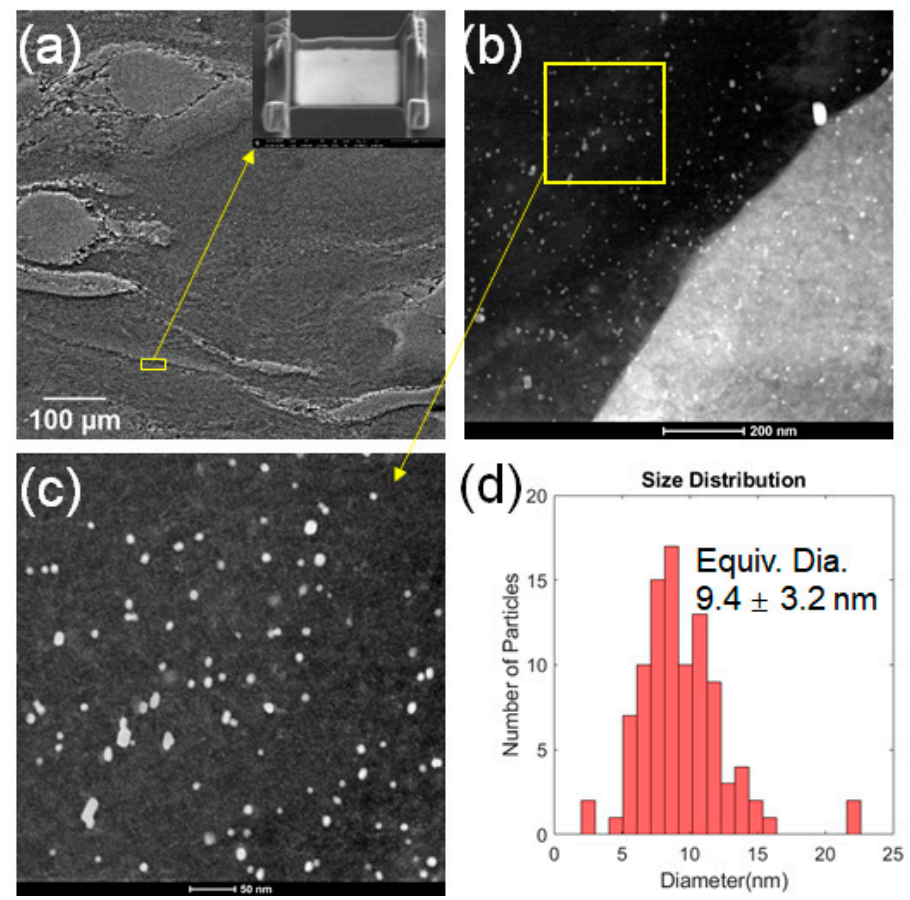

Figure 14. (a) SEM image of the selected area for FIB life-out membrane from the sample deformed to $\varepsilon_{\mathrm{t}}$ of -0.40 at $\dot{\varepsilon}$ of $10 \mathrm{~s}^{-1}$, (b) HAADF image in STEM mode for the sample lifted out in (a), (c) nano-sized $\mathrm{Zn}-\mathrm{Zr}$ particles, and (d) size distribution histogram quantified from the micrograph in (c) showing the mean equivalent diameter of these $\mathrm{Zn}-\mathrm{Zr}$ particles was about $9.4 \mathrm{~nm}$.

\section{Conclusions}

The present study investigates the microstructural evolution of an as-forged ZK30 alloy during uniaxial hot deformation at $350{ }^{\circ} \mathrm{C}$ at a high strain rate of $10 \mathrm{~s}^{-1}$. The complicated deformed microstructures were successfully separated into distinct groups of grains. Correlative imaging and a grain partitioning approach based on intra-granular misorientation analysis of EBSD measurements were used. Focus was placed on the deformation and DRX behaviours of the alloy. The following conclusions can be made from this work:

1. The PDRX phenomenon was observed in the Zr-lean regions of the ZK30 samples hot deformed to true strains ranging from -0.22 to -0.69 at a strain rate of $10 \mathrm{~s}^{-1}$. The experimental results suggested that the DRXed nucleus produced during the hot compression grew into the matrix of high stored strain energy after the deformation ceased. However, for the sample deformed to a true strain of -1.11 at the same strain rate, stored strain energy was significantly released by profuse DRX and hence, PDRX behavior was impeded.

2. A true strain of -1.11 can be achieved during the hot compression of the as-forged ZK30 alloy at a temperature of $350{ }^{\circ} \mathrm{C}$ and a strain rate of $10 \mathrm{~s}^{-1}$, without any cracks observed. The alloy exhibited excellent formability under the present deformation condition.

3. During the hot deformation at a strain rate of $10 \mathrm{~s}^{-1}$, a macro-shear band started to form at a true strain of -0.22 , and plastic strains localized to it with the deformation continued. Within the shear band, a 'necklace structure' consisting of refined DRXed grains was formed around the Zr-rich coarse grains. CDRX and DDRX via grain boundary corrugation/bulging were the dominant recrystallization mechanisms. As the deformation continued, the fraction of refined DRXed grains in the $\mathrm{Zr}$-rich domains increased and the aspect ratio of coarse grains dramatically increased. In contrast, the microstructure after hot compression at a strain rate of $10^{-3} \mathrm{~s}^{-1}$ under the same temperature was much more uniform for the same strain level. 
4. Zr-rich coarse grains, which were homogeneously distributed in the as-received microstructure, played an important role in accommodating plastic strains in the hot deformation at a high strain rate. It is speculated that the densely distributed $\mathrm{Zn}-\mathrm{Zr}$ particles of refined size reduced the ratio of the critical resolved shear stress of the prismatic slip to that of the basal slip. This contributed to the activation of prismatic slips enhancing the plasticity of coarse grains. Moreover, the high activity of prismatic slips facilitated the operation of CDRX in the vicinity of grain boundaries, which effectively relaxed the stress concentration.

5. The present study suggests that the twinning-induced DRX mechanism is not necessary for the excellent plasticity of $\mathrm{Mg}$ alloys in hot deformation under a high-strain-rate condition. Enhanced activity of non-basal slips appears to be more essential to improve the plasticity of $\mathrm{Mg}$ alloys hot deformed at a high strain rate.

Author Contributions: Conceptualization, H.Z.; methodology, J.Y., Y.H., L.H. and H.Z.; formal analysis, L.H. and H.Z.; investigation, J.Y., Y.H. and H.Z.; resources, H.Z. and L.H.; data curation, J.Y. and Y.H.; writing-original draft preparation, J.Y., Y.H. and H.Z.; writing—review and editing, H.Z. and G.Z.; visualization, J.Y., H.Z. and G.Z.; supervision, C.L.; project administration, H.Z.; funding acquisition, H.Z. All authors have read and agreed to the published version of the manuscript.

Funding: C.L. acknowledges funding from Hunan Province Key Field R \& D Program(2019WK2061).

Conflicts of Interest: The authors declare no conflict of interest.

\section{References}

1. Luo, A.A. Magnesium: Current and potential automotive applications. JOM 2002, 54, 42-48. [CrossRef]

2. You, S.; Huang, Y.; Kainer, K.U.; Hort, N. Recent research and developments on wrought magnesium alloys. J. Magnes. Alloys 2017, 5, 239-253. [CrossRef]

3. Luo, A.A. Magnesium casting technology for structural applications. J. Magnes. Alloys 2013, 1, $2-22$. [CrossRef]

4. Zhang, Z.; Yan, Z.; Du, Y.; Zhang, G.; Zhu, J.; Ren, L.; Wang, Y. Hot deformation behavior of homogenized Mg-13.5 Gd-3.2 Y-2.3 Zn-0.5 Zr alloy via hot compression tests. Materials 2018, 11, 2282. [CrossRef]

5. Quan, G.Z.; Ku, T.W.; Song, W.J.; Kang, B.S. The workability evaluation of wrought AZ80 magnesium alloy in hot compression. Mater. Des. 2011, 32, 2462-2468. [CrossRef]

6. Prasad, Y.; Rao, K. Effect of homogenization on the hot deformation behavior of cast AZ31 magnesium alloy. Mater. Des. 2009, 30, 3723-3730. [CrossRef]

7. Kim, H.; Lee, J.; Lee, C.; Bang, W.; Ahn, S.; Chang, Y. Shear band formation during hot compression of AZ31 Mg alloy sheets. Mater. Sci. Eng. A 2012, 558, 431-438. [CrossRef]

8. Jin, X.; Xu, W.; Shan, D.; Liu, C.; Zhang, Q. Deformation behavior, microstructure evolution and hot workability of Mg-3.7 Gd-2.9 Y-0.7 Zn-0.7 Zr alloy. Met. Mater. Int. 2017, 23, 434-443. [CrossRef]

9. Rao, K.; Prasad, Y.; Suresh, K.; Hort, N.; Kainer, K. Hot deformation behavior of Mg-2Sn-2Ca alloy in as-cast condition and after homogenization. Mater. Sci. Eng. A 2012, 552, 444-450. [CrossRef]

10. Xiao, H.; Jiang, S.; Tang, B.; Hao, W.; Gao, Y.; Chen, Z.; Liu, C. Hot deformation and dynamic recrystallization behaviors of Mg-Gd-Y-Zr alloy. Mater. Sci. Eng. A 2015, 628, 311-318. [CrossRef]

11. Lentz, M.; Risse, M.; Schaefer, N.; Reimers, W.; Beyerlein, I. Strength and ductility with $\{10-11\}-\{10-12\}$ double twinning in a magnesium alloy. Nat. Commun. 2016, 7, 1-7. [CrossRef]

12. Dogan, E.; Vaughan, M.; Wang, S.; Karaman, I.; Proust, G. Role of starting texture and deformation modes on low-temperature shear formability and shear localization of Mg-3Al-1Zn alloy. Acta Mater. 2015, 89, 408-422. [CrossRef]

13. Sun, D.; Chang, C. Microstructural study of strain localization in a compressed Mg-3Al-1Zn alloy. Mater. Sci. Eng. A 2014, 603, 30-36. [CrossRef]

14. Sandlöbes, S.; Zaefferer, S.; Schestakow, I.; Yi, S.; Gonzalez-Martinez, R. On the role of non-basal deformation mechanisms for the ductility of Mg and Mg-Y alloys. Acta Mater. 2011, 59, 429-439. [CrossRef]

15. Vaughan, M.; Nasim, W.; Dogan, E.; Herrington, J.; Proust, G.; Benzerga, A.; Karaman, I. Interplay between the effects of deformation mechanisms and dynamic recrystallization on the failure of Mg-3Al-1Zn. Acta Mater. 2019, 168, 448-472. [CrossRef] 
16. Jiang, L.; Jonas, J.J.; Mishra, R.; Luo, A.; Sachdev, A.; Godet, S. Twinning and texture development in two Mg alloys subjected to loading along three different strain paths. Acta Mater. 2007, 55, 3899-3910. [CrossRef]

17. Zhu, S.; Yan, H.; Chen, J.; Wu, Y.; Liu, J.; Tian, J. Effect of twinning and dynamic recrystallization on the high strain rate rolling process. Scr. Mater. 2010, 63, 985-988. [CrossRef]

18. Zhu, S.; Ringer, S.P. On the role of twinning and stacking faults on the crystal plasticity and grain refinement in magnesium alloys. Acta Mater. 2018, 144, 365-375. [CrossRef]

19. Zhu, S.; Yan, H.; Liao, X.; Moody, S.; Sha, G.; Wu, Y.; Ringer, S. Mechanisms for enhanced plasticity in magnesium alloys. Acta Mater. 2015, 82, 344-355. [CrossRef]

20. Lentz, M.; Behringer, A.; Fahrenson, C.; Beyerlein, I.J.; Reimers, W. Grain size effects on primary, secondary, and tertiary twin development in Mg-4 wt pet Li (-1 wt pct Al) alloys. Metall. Mater. Trans. A 2014, 45, 4737-4741. [CrossRef]

21. Rafailov, G.; Caspi, E.a.N.; Hielscher, R.; Tiferet, E.; Schneck, R.; Vogel, S.C. Visualization of texture components using MTEX. J. Appl. Crystallogr. 2020, 53, 540-548. [CrossRef] [PubMed]

22. Li, J.; Barrirero, J.; Sha, G.; Aboulfadl, H.; Mücklich, F.; Schumacher, P. Precipitation hardening of an Mg-5Zn-2Gd-0.4 Zr (wt.\%) alloy. Acta Mater. 2016, 108, 207-218. [CrossRef]

23. Mendis, C.; Oh-Ishi, K.; Kawamura, Y.; Honma, T.; Kamado, S.; Hono, K. Precipitation-hardenable Mg-2.4 Zn-0.1 Ag-0.1 Ca-0.16 Zr (at.\%) wrought magnesium alloy. Acta Mater. 2009, 57, 749-760.

24. Sha, G.; Zhu, H.; Liu, J.; Luo, C.; Liu, Z.; Ringer, S. Hydrogen-induced decomposition of Zr-rich cores in an $\mathrm{Mg}-6 \mathrm{Zn}-0.6 \mathrm{Zr}-0.5 \mathrm{Cu}$ alloy. Acta Mater. 2012, 60, 5615-5625. [CrossRef]

25. Hadadzadeh, A.; Mokdad, F.; Amirkhiz, B.S.; Wells, M.; Williams, B.W.; Chen, D. Bimodal grain microstructure development during hot compression of a cast-homogenized Mg-Zn-Zr alloy. Mater. Sci. Eng. A 2018, 724, 421-430. [CrossRef]

26. Wright, S.I.; Nowell, M.M.; Field, D.P. A review of strain analysis using electron backscatter diffraction. Microsc. Microanal. 2011, 17, 316-329. [CrossRef]

27. Wright, S.I.; Suzuki, S.; Nowell, M.M. In situ EBSD observations of the evolution in crystallographic orientation with deformation. JOM 2016, 68, 2730-2736. [CrossRef]

28. Yoda, R.; Yokomaku, T.; Tsuji, N. Plastic deformation and creep damage evaluations of type 316 austenitic stainless steels by EBSD. Mater. Charact. 2010, 61, 913-922. [CrossRef]

29. Rui, S.-S.; Shang, Y.-B.; Fan, Y.-N.; Han, Q.-N.; Niu, L.-S.; Shi, H.-J.; Hashimoto, K.; Komai, N. EBSD analysis of creep deformation induced grain lattice distortion: A new method for creep damage evaluation of austenitic stainless steels. Mater. Sci. Eng. A 2018, 733, 329-337. [CrossRef]

30. Feng, A.H.; Ma, Z.Y. Microstructural evolution of cast Mg-Al-Zn during friction stir processing and subsequent aging. Acta Mater. 2009, 57, 4248-4260. [CrossRef]

31. Jiang, M.G.; Xu, C.; Yan, H.; Fan, G.H.; Nakata, T.; Lao, C.S.; Chen, R.S.; Kamado, S.; Han, E.H.; Lu, B.H. Unveiling the formation of basal texture variations based on twinning and dynamic recrystallization in AZ31 magnesium alloy during extrusion. Acta Mater. 2018, 157, 53-71. [CrossRef]

32. Sakai, T.; Belyakov, A.; Kaibyshev, R.; Miura, H.; Jonas, J.J. Dynamic and post-dynamic recrystallization under hot, cold and severe plastic deformation conditions. Prog. Mater. Sci. 2014, 60, 130-207. [CrossRef]

33. Sitdikov, O.; Kaibyshev, R. Dynamic recrystallization in pure magnesium. Mater. Trans. 2001, 42, $1928-1937$. [CrossRef]

34. Eleti, R.R.; Chokshi, A.H.; Shibata, A.; Tsuji, N. Unique high-temperature deformation dominated by grain boundary sliding in heterogeneous necklace structure formed by dynamic recrystallization in $\mathrm{HfNbTaTiZr}$ BCC refractory high entropy alloy. Acta Mater. 2020, 183, 64-77. [CrossRef]

35. Huang, K.; Logé, R. A review of dynamic recrystallization phenomena in metallic materials. Mater. Des. 2016, 111, 548-574. [CrossRef]

36. Cruz-Gandarilla, F.; Bolmaro, R.; Mendoza-León, H.; Salcedo-Garrido, A.; Cabañas-moreno, J. Study of recovery and first recrystallisation kinetics in CGO Fe3\% Si steels using misorientation-derived parameters (EBSD). J. Microsc. 2019, 275, 133-148. [CrossRef] [PubMed]

37. Solas, D.E.; Tome, C.N.; Engler, O.; Wenk, H.R. Deformation and recrystallization of hexagonal metals: Modeling and experimental results for zinc. Acta Mater. 2001, 49, 3791-3801. [CrossRef]

38. Lassila, D.H.; Leblanc, M.M.; Florando, J.N. Zinc single-crystal deformation experiments using a " 6 degrees of freedom" apparatus. Metall. Mater. Trans. A 2007, 38a, 2024-2032. [CrossRef] 
39. Yan, C.K.; Feng, A.H.; Qu, S.J.; Cao, G.J.; Sun, J.L.; Shen, J.; Chen, D.L. Dynamic recrystallization of titanium: Effect of pre-activated twinning at cryogenic temperature. Acta Mater. 2018, 154, 311-324. [CrossRef]

40. Galiyev, A.; Kaibyshev, R.; Sakai, T. Continuous dynamic recrystallization magnesium alloy. Mater. Sci. Forum 2003, 419-422, 509-514. [CrossRef]

41. Sakai, T.; Ohashi, M.; Chiba, K.; Jonas, J. Recovery and recrystallization of polycrystalline nickel after hot working. Acta Metall. 1988, 36, 1781-1790. [CrossRef]

42. Djaic, R.P.; Jonas, J. Recrystallization of high carbon steel between intervals of high temperature deformation. Metall. Trans. 1973, 4, 621-624. [CrossRef]

43. Petkovic, R.; Luton, M.; Jonas, J. Recovery and recrystallization of polycrystalline copper after hot working. Acta Metall. 1979, 27, 1633-1648. [CrossRef]

44. Nicolaÿ, A.; Fiorucci, G.; Franchet, J.; Cormier, J.; Bozzolo, N. Influence of strain rate on subsolvus dynamic and post-dynamic recrystallization kinetics of Inconel 718. Acta Mater. 2019, 174, 406-417. [CrossRef]

45. Robson, J.; Paa-Rai, C. The interaction of grain refinement and ageing in magnesium-zinc-zirconium (ZK) alloys. Acta Mater. 2015, 95, 10-19. [CrossRef]

46. Bhattacharyya, J.; Sasaki, T.; Nakata, T.; Hono, K.; Kamado, S.; Agnew, S. Determining the strength of GP zones in Mg alloy AXM10304, both parallel and perpendicular to the zone. Acta Mater. 2019, 171, 231-239. [CrossRef]

47. Chapuis, A.; Driver, J.H. Temperature dependency of slip and twinning in plane strain compressed magnesium single crystals. Acta Mater. 2011, 59, 1986-1994. [CrossRef]

48. Nie, J.F. Effects of precipitate shape and orientation on dispersion strengthening in magnesium alloys. Scr. Mater. 2003, 48, 1009-1015. [CrossRef]

49. Chaudry, U.M.; Hamad, K.; Kim, J.-G. Ca-induced Plasticity in Magnesium Alloy: EBSD Measurements and VPSC Calculations. Crystals 2020, 10, 67. [CrossRef]

50. Masood Chaudry, U.; Hoo Kim, T.; Duck Park, S.; Sik Kim, Y.; Hamad, K.; Kim, J.-G. On the high formability of AZ31-0.5 Ca magnesium alloy. Materials 2018, 11, 2201. [CrossRef]

51. Sánchez-Martín, R.; Pérez-Prado, M.; Segurado, J.; Bohlen, J.; Gutiérrez-Urrutia, I.; Llorca, J.; Molina-Aldareguia, J. Measuring the critical resolved shear stresses in $\mathrm{Mg}$ alloys by instrumented nanoindentation. Acta Mater. 2014, 71, 283-292. [CrossRef] 